Illinois State University

ISU ReD: Research and eData

Theses and Dissertations

6-26-2017

\title{
Over the Ropes: Boundary Play in Professional Wrestling
}

Ethan Ingram

Illinois State University, eingram@ilstu.edu

Follow this and additional works at: https://ir.library.illinoisstate.edu/etd

Part of the Social and Cultural Anthropology Commons, and the Theatre and Performance Studies Commons

\section{Recommended Citation}

Ingram, Ethan, "Over the Ropes: Boundary Play in Professional Wrestling" (2017). Theses and Dissertations. 757.

https://ir.library.illinoisstate.edu/etd/757

This Thesis is brought to you for free and open access by ISU ReD: Research and eData. It has been accepted for inclusion in Theses and Dissertations by an authorized administrator of ISU ReD: Research and eData. For more information, please contact ISUReD@ilstu.edu. 


\section{OVER THE ROPES: BOUNDARY PLAY IN PROFESSIONAL WRESTLING}

\section{Ethan Ingram}

\section{Pages}

Within the anthropology of performance, scholars have traditionally considered theater, spectacle, sport, and ritual performances in terms of the discrete boundaries of space and time that separate these events from daily life and in terms of the disparate roles that demarcate performers from audience members. Professional wrestling, a popular performance genre in the American Midwest, exhibits features that challenge these boundaries through the collaborative construction of the event by performers and audience members. Audience interaction is an essential part of wrestling performances, characterized by routine and contextually understood behaviors that performers can process as evaluative feedback. Moreover, during wrestling matches, performers interact directly with audience members in unexpected, unplanned, and sometimes dangerous ways. In doing so, wrestlers engage in what I define as "boundary play," the establishment and subsequent transgression of rules and boundaries that are assumed to characterize the performer-audience relationship. Through boundary play, the apparent social order of a performance event is disrupted and the relationship between what is "real" and what is dramatic fiction is deliberately made ambiguous. The simulated and stylized violence displayed in wrestling, as well as the constant possibility for real injury, serves as a primary mode of interaction between performers that draws powerful affective responses from the audience. The use of boundary play in professional wrestling requires and cultivates a relationship between performers and audience members based on mutual trust and consent. Wrestling becomes "real" 
when this close interaction allows the performance to become a collaborative practice shared by all participants.

While much of the public and scholarly interpretation of wresting focuses on the xenophobic, sexist, and otherwise problematic narratives embedded in some wrestling performances, I believe that a focus on the role of boundary play in these performances challenges the public and academic perception of wrestling as a "dangerous" performance that thrives on social tension and the audience's fear of the other. "Believing" in wrestling implies a commitment that is stronger than suspension of disbelief in that it represents a constant and everchanging dialogue between performers and audiences concerning what is "real" and what is "fake." I propose that boundary play allows wrestling to be an effective medium for the moralizing narratives that it conveys, which have historically been hegemonic in nature, but can also act subversively.

KEYWORDS: Performance, Play, Professional Wrestling 
OVER THE ROPES: BOUNDARY PLAY IN PROFESSIONAL WRESTLING

\title{
ETHAN INGRAM
}

\author{
A Thesis Submitted in Partial \\ Fulfillment of the Requirements \\ for the Degree of \\ MASTER OF SCIENCE \\ Department of Sociology and Anthropology \\ ILLINOIS STATE UNIVERSITY
}

2017 
Copyright 2017 Ethan Ingram 
OVER THE ROPES: BOUNDARY PLAY IN PROFESSIONAL WRESTLING

\section{ETHAN INGRAM}

COMMITTEE MEMBERS:

Gina Hunter, Chair

James Stanlaw

Angela Glaros 


\section{ACKNOWLEDGMENTS}

It takes a village to raise a child; for the graduate student, it takes multiple villages. And this is doubly true for anthropologists, who pride themselves on all of the villages they've stumbled into. Throughout the long and stressful process of writing this work, I have had the privilege of being supported by the finest community of scholars, family, and friends that I could ask for. I will never be able to thank them enough, but let this work stand as a testament to their gratitude.

My parents, Jack and Cris Ingram, have supported me through two academic degrees and all the myriad pursuits that have come with them. Thank you for all of your love and constant support. And to my brother, Tyler, who attended many matches with me during my research, thanks for devoting your evenings to driving to god-knows-where to watch a bunch of sweaty men throw each other around.

The completion of this thesis is as much a product of my committee's patience as it is my persistence. My advisor and chair, Gina Hunter, has been an invaluable mentor, editor, and critic throughout my time at Illinois State University, and has guided me through this process with far more kindness and understanding than I've deserved. James Stanlaw, who has always been someone who I could come to with asinine and arcane questions concerning whatever bit of anthropological theory I was reading, has also inspired me: your guidance encourages me to consider the unordinary and to make the familiar as strange as possible. I hope the research that I have conducted here is something you can both be proud of. Thank you also to the Anthropology Department faculty and staff who have fostered this excellent teaching and research community that I have called home for the last three years. 
Angela Glaros, also on this committee, has been a constant champion of my work as a scholar, and has always pushed me towards success when I didn't think I could go any further. She has always believed in me, especially when I couldn't believe in myself, and I wouldn't be where I am today without her wisdom and compassion. I am honored to call you my mentor and my friend, and can never thank you enough for all you've done for me.

I must also mention Don Holly, who taught my first anthropology class at Eastern Illinois University and is thus responsible for sparking the passion that I hold for this field. His example as an instructor, researcher, and mentor sets the model for what I aspire to be. The Anthropology department at EIU—-literally just Don and Angela — are two of the hardest working and most passionate people I know. They have had an immeasurable impact on their students, and I am glad to say that I am one of them.

Finally, you don't really get to choose your friends in graduate school; they've been preselected by the admissions committee. Thankfully, I could not have asked for a better cohort of students, graduate and undergraduate, to suffer and celebrate alongside. I have been helped immensely by their general and - in the case of the wrestling fans among them - theoretical inspiration. And so, I would like to thank Paula Bryant, Jesse Slater, Dylyn Hennenfent, Dustin Lloyd, Jacklyn Weier, Amanda Miller, Hannah Meyer, Dan Walther, Jordan Prats, and everyone else who has shared this journey with me. And I would especially like to thank Kelsey Hanson, a mentor in her own right, whose friendship and advice have been invaluable and whose own success continues to motivate me.

E. I. 


\section{CONTENTS}

Page

ACKNOWLEDGMENTS

$\begin{array}{ll}\text { CONTENTS } & \text { iii }\end{array}$

INTRODUCTION

$\begin{array}{ll}\text { The Field Site } & 2\end{array}$

Methods and Chapter Overview $\quad 8$

CHAPTER I: THE GREAT AMERICAN THROWDOWN 11

CHAPTER II: "PERFECT BASTARDS” 25

A Brief History of American Wrestling 25

Wrestling and Ritual Theatre 26

Professional Wrestling as Mass Media 30

Wrestling as Live Performance 33

CHAPTER III: BOUNDARY PLAY AND WRESTLING PERFORMANCES 36

The Boundaries of Wrestling Performance $\quad 50$

$\begin{array}{ll}\text { Structural Boundaries } & 52\end{array}$

$\begin{array}{ll}\text { Spatial Boundaries } & 55\end{array}$

$\begin{array}{ll}\text { Interactional Boundaries } & 57\end{array}$

CHAPTER IV: AN ANATOMY OF A FAILED PERFORMANCE 64

$\begin{array}{ll}\text { The Main Event } & 66\end{array}$

The Post-Mortem: When Heat Fails to Catch 76

CONCLUSION: TAKING WRESTLING SERIOUSLY 83

$\begin{array}{ll}\text { REFERENCES } & 87\end{array}$

iii 


\section{INTRODUCTION}

Imagine my surprise when, during my very first outing to a local wrestling event, one of the wrestlers jumped out of the ring and grabbed an audience member by the throat, bringing him eye-to-eye and muttering some nasty threat. My shock was not matched by the assailed; in fact, he seemed pretty happy to be receiving the attention. I was even more surprised a few weeks later, when an extremely large man lunged through the ropes directly into what was a seated crowd, crash-landing into the folding chair I was sitting in, now a twisted and useless hunk of metal. Had I not been so quick in getting out of the way, the "fakery" of professional wrestling would have resulted in the very real injury to my own person. This was the first time a man was thrown at me during a match, but it certainly wasn't the last. This example of boundary play, what appears to be a radical and risky violation of personal boundaries is actually quite routine, a regular part of doing business for the wrestling's performers. For audience members, this apparent chaos becomes something that must be adapted to. While the actors in professional wrestling - explicitly defined as the wrestlers, referees, and other characters of the wrestling drama - are typically the ones to instigate boundary play, the audience reacts through contextually understood responses to the actions of the performers. It is here that we must challenge an understanding of the audience member as a "pure" spectator, and instead consider the performative qualities of spectating itself. These performances, as I came to learn very quickly, are something that must be learned through practice. And amongst the individuals in a wrestling crowd there are varying degrees of permissiveness and consent of the wrestlers' behaviors towards them. If it was my throat that was throttled during that first match, I probably would have fled the wrestling scene, never to return. If this happened to me a year later or so, I would be overjoyed. Professional wrestlers are incredibly skilled performers. Not only are they 
proficient in wrestling itself — straining, painful, and sometimes incredibly dangerous labor-but they are masters of understanding their audience. There is a constant, background communication between the performers within the ring and those sitting around it; as they "read" an audience, and what they are willing to permit, they adjust their performances accordingly. The wrestling drama, then, is not played according to a script. It is instead a dialogue between two distinct but intertwined sets of performers; while certain aspects of a performance may be predetermined, there is a great deal of freedom for the wrestlers to reach these set points in the ways that they see fit.

\section{The Field Site}

The ethnographic fieldwork for this research was primarily conducted in a period spanning one year, beginning in September of 2014 and ending in the fall of 2015. During this time, I made frequent and regular trips to attend live professional wrestling events produced by several promotions across central Illinois. For the purposes of this research, I broadly define "central Illinois" as the geographic area bordered by St. Louis to the south and the greater Chicagoland area to the north. This area is characterized by small rural and working class communities with some modestly sized metropolitan areas, such as Champaign-Urbana, Peoria, and the state capital of Springfield interspersed in between. While it is these more populated cities that often feature the most active promotions, professional wrestling can be found throughout the central Illinois area. Bloomington-Normal, the community in which I have resided throughout this research, has no wrestling promotions of its own. But to my initial surprise, I never had to look to far to find wrestling going on at any given time, and most of the shows that I attended were approximately an hour's drive away from where I was staying. 
While I do not have an exact total, I would estimate that I have attended approximately 50-60 professional wrestling shows. These events typically last two hours, consisting of four to five matches with an intermission and preparation time in between. At the most "prestigious" shows I attended, a night of wrestling would go as long as four hours, ending close to midnight. These shows could feature up to ten different matches, but sometimes featured top-billed matches between popular wrestlers that could last up to an hour on their own. As a wrestling spectator, I joined crowds usually numbering between 30-50 people at an event, with more prestigious and publicized shows drawing up to 300 people. At smaller shows, the people present were often long-term and regular fans, coming back week after week to see shows offered by a single promotion. Some of these fans also made the rounds of other promotion's shows, becoming familiar faces in the small but stable community of Illinois wrestling fans.

The crowds at these events represent an array of backgrounds and stand in contrast to a wrestling audience that has been historically categorized as exclusively white, male, and working class. Certainly, there were plenty of white men of apparent working class backgrounds at these shows; there was also a significant population of black and Latino fans as well. Women made up a surprisingly large portion of the attendance base. The wrestlers generally reflected this population as well, although the wrestlers that I saw were predominantly men. In central Illinois, women wrestlers are vastly outnumbered by their male counterparts. In my fieldwork, I saw two or three women who were regular, "local" wrestlers, and just a few more that came as touring, independent performers. In nearby Chicago, which has a unique wrestling community of its own, women wrestlers are far more common. (There is one popular promotion based in Chicago whose entire stable of wrestlers is composed of women performers.) More recently, local 
wrestling promotions have become interested in developing their women's wrestling divisions, and these numbers have been slowly increasing.

Children of all ages were a common presence at these events, which may initially come as a surprise due to professional wrestling's violent nature and the potentially risky situations that may incur when wrestlers take the action out of the ring and into the audience's space. But it should be noted that children are an expected wrestling audience and promotions and performers consider the content of their performances with this in mind. All of the events that I attended were, in one way or another, explicitly marketed as "family-friendly" entertainment. The major restriction on the wrestlers to maintain this labeling was on their language-swearing was discouraged for audience members and generally prohibited for the wrestlers. (Though the occasional slip of the tongue by performers was not uncommon, in my experience.) Beyond this prohibition, children were treated essentially the same as any other audience member. Some kids were particularly vocal and excited in their verbal assault against villainous wrestlers, and these wrestlers would respond in kind.

I would surmise that the actual wrestling on display at these events was not hindered or softened in order to keep it "safe" for younger audiences. There are some wrestling promotions that specialize in "extreme" content. At these shows, wrestlers show a propensity for vivid and bloody_-but still superficial—violence, attacking each other with sharp, nasty, and sometimes inventive weapons (staple guns, fluorescent light tubes, cheese graters, etc.) But wrestling that capitalizes on its gruesomeness has fallen out of vogue as of late, and none of the local promotions that I am aware of deal in wrestling that could be defined as extreme in this fashion. The wrestling on display in Illinois's local promotions falls in line with what you will find on mainstream televised productions such as WWE Raw, which is itself heavily marketed towards 
and watched by children. The physical violence in wrestling demonstrates force and brutality, but bloodshed is rare and never egregious. The most common weapons I saw being used were the folding chair and the trashcan - effective in their own right but not intended to cut, slash, or pierce. Generally, wrestling violence is considered appropriate and engaging for audiences of all ages, and the wrestling environments in central Illinois are a safe place for children to enjoy this entertainment even when the action becomes a source of possible danger for audience members. During wrestling matches I have seen wrestlers attack each other inches from myself and others. I have had to leap out of the way as objects and bodies were flung and thrown at where I was sitting. But in all of the matches I have attended, I have never seen an audience member, and especially not a child, come to any undue stress or harm on account of the performers. This speaks to an important aspect of the nature of professional wrestling: in as much as it appears to be wild and chaotic, wrestling performances are also the result of careful planning and consideration of risk mitigation. Every individual audience member has their own level of acceptable engagement; for wrestlers, recognizing and maintaining this tacit consent is paramount to a successful wrestling experience.

My direct experience with local wrestling has been mostly limited to events offered by three promotions. While there are many promotions operating within central Illinois (at one point, I counted a dozen advertising online), my intention in following certain promotions was to observe how a single promotion would remain consistent or change over time and to become familiarized with both the wrestlers and audience members that would frequent a specific site. The first of these promotions, "Zero1 Wrestling," was selected primarily due to convenience: this promotion offered weekly shows at a time that I could attend in a city that was very close by. Once I had become familiar with Zero1's offerings, the other two promotions, "United Wrestling 
Coalition" (UWC) and "Dreamwave Wrestling," were selected based on recommendations from people I talked with at matches and through the information that was publicized online. While it was not my initial intent, the promotions that I followed also became a good representation of the variety of experiences offered by local wrestling producers. Zero1 and UWC were modestly successful and locally popular promotions that offered frequent shows to smaller audiences. Dreamwave, on the other hand, was widely known as the best wrestling available south of Chicago. Dreamwave only put on one show a month, but those events were attended by hundreds of fans from around the state. In addition to the local "pool" of wrestlers who appeared in promotions across the region, Dreamwave also drew on talent from nationally recognized promotions across the country and former wrestling superstars and their own exclusive local performers, some of whom have gone on to wrestle for the WWE. That is not to say that Zero1 and UWC were "bad" promotions by any means; indeed, some of the most memorable and exciting experiences I had were at their matches. But it should be noted that not all local wrestling can be considered equal, and that success in one promotion may come at the detriment to another.

My introduction to Illinois professional wrestling came at a fortunate time, with several local promotions experiencing an upswing in attendance and productivity. In the first fall and winter of my field research, I was attending at least one wrestling show a week and hardly covering all of the opportunities to see local wrestling that were readily available. During this period, the particularly avid wrestling fan could have seen at least two or three shows a week if they were willing to devote the time and money necessary to make the trip. (In the field, I have met several people who were so inclined to make this commitment.) As these local promotions were drawing from a relatively small pool of local talent, the wrestlers at these events were also 
kept busy during this time. In some cases, I could watch a match on a Thursday evening and see the same wrestlers back in the ring on Friday, this time in a town two to three hours away from where they started. With professional wrestling occurring almost constantly in the area, I was initially a little amazed that such fervent activity could be maintained for an extended period of time. But I have since learned that this initial period was not necessarily the norm. Professional wrestling is an exercise in managed chaos, and this holds true for operations in and out of the ring. From the time I started this research three years ago to now, the face of local wrestling has changed in many ways. Zero1 and UWC, who have long been well regarded in the community, still remain. But while they once held weekly shows, they have since reduced their events to one every few months. Dreamwave ended 2016, its most profitable and well attended year in the promotion's history, by shutting down for good, and has since been replaced by another high-end promotion coming out of Chicago. New promotions have opened their doors and closed after one show, while other newcomers have become popular and well-loved producers. Local wrestling is tumultuous, but its devotion to the community remains persistent. Wrestling is wrestling, to a certain extent, and fans continue their regular devotion no matter whose logo is on the card.

All of the promotions that I have become familiar with through this research could be generally defined as "indie," or independent, professional wrestling. This is a self-ascribed label that is taken with some pride in the wrestling community, where indie wrestling promotions are seen as providing an alternative experience to the wrestling provided by the WWE, which has held an effective monopoly on national wrestling media for the last twenty years. But "indie wrestling" describes a wide-range of wrestling producers that differ in audience size, media outreach, and production quality. (Indeed, in the American context, indie wrestling could perhaps be best defined as any professional wrestling not occurring under the banner of the WWE.) Even 
locally, wrestling promotions vary widely, and can be roughly ranked in terms of the "quality" of their product. At the low end, there are the truly amateur productions, featuring inexperienced performers, makeshift equipment. These promotions typically don't last long and face a stigma within the larger wrestling community, seen as both unsafe and a poor representation of what local indie wrestling can provide. On the other end, there are promotions that can truly be called "professional" which often have the ability to draw audiences from a wider geographic range and can, in some cases, showcase talent that becomes recognized by larger, nationally renowned promotions.

\section{Methods and Chapter Overview}

Professional wrestling, despite its apparent, brute simplicity, is an incredibly complicated subject. In choosing to focus on the performative relationships between performers and audiences, I necessarily neglect a great deal of what could and ought to be said about the role of wrestling as a social, economic, and historical practice. I tend to approach any ethnographic work to be a sort of "invitation," a plea for others to consider some practice as significant and valuable and to interact with through their own subjective experiences.

The thesis is divided into four chapters, each engaging different aspects of professional wrestling performance. Chapter 1 is an ethnography of a wrestling event based on my participant observation which lays out why this issue of boundary play is important to understanding wrestling. In Chapter 2, "Perfect Bastards," I survey the ways in which professional wrestling and its audiences have been theorized about by scholars from a wide variety of fields. In many cases, this research has served as an interpretation of the politically and socially salient aspects of the wrestling drama and its narratives, as well as descriptions of the "theatrical" and performative strategies that both wrestlers and audiences rely on. While this literature has informed my own 
understanding of wrestling, I also challenge the typical ways in which wrestling has been conceptualized through the focus on certain types of wrestling performances and the exception of others. In doing so, I frame my research in the context of the unique community that I followed. I will detail the ways in which wrestling is practiced amongst this community, some general aspects of the community members that I interacted with, and my own process of becoming a wrestling fan.

In Chapter 3, I focus specifically on the concept of boundary play as it is employed in wrestling performances. The ambiguity of boundaries in professional wrestling is generally produced through two forms of strategies from wrestling actors: the "pushing" of certain dramatic behaviors into the "real" experience of the audience, and the "pulling" of real events, such as mistakes, into the wrestling drama. Often, these actions feature violence or other aggressive behavior as central features. I will also look at the performative role and responsibilities of the wrestling audience, how audience performances are learned, and how communication is established between wrestlers and the audience.

In Chapter 4, I describe one instance that I experienced in which the usual communication between performers and audience was not realized. Based on the circumstances of one wrestling event, most notably an unfamiliar audience in a unique space, the wrestlers could not attempt to enact the boundary play that characterizes their performance. As a result, the typical "wrestling experience" that this promotion creates could not fully materialize, much to the frustration of both the wrestlers and the regular fans in the crowd (myself included). This example emphasizes the importance of audience performances in the production of wrestling, as well as the role of the audience's consent in how wrestlers conduct their own performances. 
Throughout these chapters, I will often rely on detailed descriptions of my experiences while in the field: the characters I ran into, the conflicts that ensued, and especially my own responses as a participant. As with any other cultural performance, professional wrestling is a sensorial and embodied experience that attempts to put its practitioners into a certain emotional state. While any wrestling match exhibits certain general features, each is wholly unique and cannot be replicated. So in addition to my theoretical considerations of wrestling practice, I felt it necessary to engage with my personal ethnographic experience through the method of thick description (Geertz 2005[1973]). Provided that the reader does not experience wrestling for themself, it falls on my abilities as an ethnographer to reproduce my own experiences, and to convey the ways that wrestling can become a transformative experience for those that take part in it. 


\section{CHAPTER I: THE GREAT AMERICAN THROWDOWN}

In the course of my fieldwork, and through my best efforts to follow the ethnographer's duty of "making the familiar strange and the strange familiar," I have come to recognize a ubiquitous, nearly nostalgic process of "looking back," a recalling of moments once regarded as ecstatic and mystifying, now reduced to the routine. I would like to begin my inquiry with one such recollection. At the time of this event's occurrence, I walked away feeling wholly and radically decentered, not to mention unsettled. I think this was a "eureka moment," wherein I saw my own behaviors — indeed, my own subjectivity — as altered, the product of the transformative power of larger social forces. Transformed, I now regard this process, the unconscious adoption of an unfamiliar role to fit a greater drama, as part and parcel of the collective ritual into which I was drawn. Now labeled and contextualized, the process is no less potent, but is now routine, stripped of its element of surprise. This is, perhaps, the cost of our attempt to understand.

It was a regular sort of night in mid-January in the American Midwest. While the air outside was frigid, I sat sweating in an auditorium that had become unbearably humid. The small space was packed to its limits: those lucky enough to find a seat sat shoulder to shoulder, while a throng stood at the periphery. The crowd fixed its rapt attention not to a distant stage or far-off spectacle, but towards its center, where the wrestling ring had been set up. I was sitting twenty feet or so from the action. The noise of this place was consuming, a couple hundred voices screaming, cheering, booing at will, occasionally meeting to form a unified chant. My own voice added to this chaos, and I could feel my throat growing hoarse. We shouted to give our encouragement. Harker Dirge, the champion that we had chosen — and who had been chosen for us - was up against the ropes, the victim of a brutal, relentless pummeling by his opponent, Frank Wyatt. In this case, I speak figuratively; more literally, Harker Dirge had been thrown 
against the chain link fence that was erected on the special occasion of the night's main event, a steel cage match for the title of the Zero1 Supreme National Heavyweight Champion. While this fight stood on its own, it was also the culmination of an ongoing clash between two rivals.

At the start of this season, and the start of my research, Harker Dirge wore the championship belt, but the title had soon after been stolen by Wyatt through foul play, leaving the former champion in disgrace. Dirge spent the following months wrestling his way to the top, for a chance to win back what was rightfully his. But Frank Wyatt was a clever opponent who did not relinquish glory easily. Whenever Harker Dirge got too close to success, Wyatt would pull the strings: sending other wrestlers to fight in his stead, invalidating matches by breaking the rules, always retaining his place at the top. Fate, it seemed, would no longer abide this game of cat-and-mouse, and on that January night, hero and villain were literally locked in together, forced to settle this feud the old-fashioned way.

The rules for winning a steel cage match are deceptively simple. Two lengths of chainlink fence, one atop the other, are lashed around the edges of the ring with a small opening of entering and exiting. The first wrestler to step outside of the cage is declared the victor. For Harker Dirge, however, the affair was significantly complicated, considering the six-footsomething, 300+ pound giant standing in his way. As he always did, Dirge started the match strong, seemingly invincible. Although Harker Dirge was in his mid-to-late forties, significantly older than most of the other wrestlers around, he was nevertheless impeccable in both his athletic physique and his wrestling skill. While he had his own reputation as a fierce, sometimes unruly, competitor, Dirge's movements and techniques were clean, technical, and planned. Frank Wyatt, on the other hand, was a brawler, specializing in wild, grueling brutality. His signature move was the "Axe Bomber," a short, punching clothesline to the throat that never failed to leave his 
opponents in crumpled heaps on the ground. Wyatt had weathered the early assault, and it was now time for Harker Dirge to become the victim.

By this point, both wrestlers were a mess. Wyatt, with exposed body completely red and unkempt hair drenched and flicking sweat, threw himself at his cruel work with all the grace of a freight train. Dirge, receiving the attack, sold his suffering: head hung limp and swaying towards his chest, stomach heaving, body slack against the corner of the ring. The rough links of the cage impressed a lattice onto his back, in some places becoming red, raw scrapes. A momentary glance outwards and I remember the presence of a third actor, creeping around the ring. Dexter, one of Frank Wyatt's cronies, had snuck back to the action to occasionally pester Dirge when he got too close. The referee, standing right next to me amidst the crowd, shooed Dexter away but made no real effort to clear him out. Since the cage kept him from doing any real damage, he was now left mostly forgotten, pacing and plotting his next move.

As is usual in the wrestling dramas that I've since become familiar with, this was not the end for Harker Dirge. Though beaten and beleaguered, he finds in the crowd's support the will to persevere and overcome his opponent, thus dealing out in kind what he received from Frank Wyatt. This succession of events that I describe, of one wrestler wholly dominating the other, and then being dominated, forms the cadence of a typical match (Barthes 1972[1957]). As this routine draws on, the audience begins to feel the exhaustion that is being physically produced in the ring. We are left wanting for a conclusion, a final act that promises justification for the preceding rhythm of violence. After forty minutes of back-and-forth, this particular match appeared to be nearing its end. Though apparently on their last legs a minute prior, both wrestlers resumed their struggle with a fresh vigor. In a moment of reprieve, Frank Wyatt began to wind up his arm, a signal to the crowd (and perhaps to Harker Dirge as well) that he was about to 
attempt the Axe Bomber, which would spell sudden death to his opponent were it to successfully land. A now wild crowd alerted Harker Dirge to the danger as Wyatt barreled full-tilt at him from across the ring. But Dirge was too quick; at the last moment, he ducked the blow, pivoted around, and took Frank Wyatt's legs out from under him, bringing him to the ground. Harker Dirge's greatest nemesis was now stymied, seemingly for good. If the applause I heard was to be believed, my own excitement was shared by everyone else in the room; as Dirge made his way to the cage's door, and thus to his victory, we expected to enjoy a justice that had been long in the making.

As Dirge made his way down the steps, the referee's signal for the ending bell never came. We had all forgotten Dexter, who had previously crept out and around the crowd and had now sapped the referee in the back of the head, leaving him unconscious. (All of this took place just a couple of feet from where I sat.) Realizing the ploy, an astonished and outraged Harker Dirge lunged for Dexter, who responded by furiously swinging his makeshift billy club. Everything leading up to this point was prologue, and now the trial began in earnest. Dirge easily overpowered Dexter, but Dexter was fast enough to lead him on a chase around the ring and through the aisles between seats. The crowd was long since passed the point of insane fervor, and now fled the combatants as the entire auditorium became the ring. Throughout, the referee lay face down on the ground; though some shouted at him to get up, nobody tried to help him or otherwise make contact. Frank Wyatt had now recovered, and seeing the game afoot came out to meet the others. Harker Dirge wrestled against two foes in tandem, throwing now-abandoned folding chairs aside as the crowd stood in clumps around the room, looking on. At this point, it had become obvious to me the depressing turn that this narrative would take, and now it was just a matter of waiting. Sure enough, Frank Wyatt's master plan took hold: Dexter got the undivided 
attention of Harker Dirge, and led him on a chase around the ring and back into the cage, leaving Wyatt alone on the outside. He did not hesitate in shaking the referee out of unconsciousness. Now miraculously recovered, the referee saw Frank Wyatt next to him and Harker Dirge still in the cage and-ignoring the third combatant, and the unprecedented attack against his own person — made the final call. Frank Wyatt had again "won" the match, and retained the title of heavyweight champion. Taking back his championship belt, Wyatt was uninterested in relishing in his victory and made a quick getaway backstage. The crowd went quickly from general fervor, to quiet astonishment, and finally condensing to an unequivocal and blistering rage.

This was the moment I recognized the unsettling change in myself. In my experience with professional wrestling up to this point, it had been no issue to shape my own performances to what was expected of me as a bystander: cheering for the heroes, booing for foul play, throwing short jabs and insults at the wrestlers when appropriate. There was a general enjoyment in "playing along" in this way, but I always considered my actions as distanced from my emotional engagement with the drama. Now, however, I was truly and honestly enraged. An authentic anger-for Wyatt and Dexter, for dissatisfaction with the drama's outcome, for this grievous miscarriage of justice — boiled up inside, and I can't say that my shouting was completely "playing along" at this point. The show was over, but there was still a final scene to be played. A now devastated Harker Dirge remained in the cage, alone with Dexter, chuckling at his cleverness in this conspiracy. Dirge took him by the hair and forced him to his knees. Now, as if in the ancient coliseum, Dirge looked to the crowd for a final verdict. A lustful call for retribution, tinged with both rage and savage glee, was the response. I too watched with disturbing glee as the disgraced champion begins, to paraphrase Barthes, to "make the bastard 
pay" (Barthes 1972[1957]). While this match was a failure for Harker Dirge, he too was a "victor" in our eyes, at last establishing some sort of justice, no matter how brutal.

Following this crushing dénouement, I was immediately intrigued, not to mention perturbed by these feelings of despair and apparent bloodlust that this match had produced within me. Shocking enough on its own, this response was almost unprecedented considering what I assumed that I understood about the "reality" of the professional wrestling that I had been closely following for several months prior. The scenes that I have described from that night, as in every other night that I spent at the ring, were a "fake." Certainly, there is some degree of reality to the event that cannot be denied. The wrestlers were enclosed in a real steel cage, but the trickery surrounding it was planned and understood by both competitors (and the audience). There was real physicality between Harker Dirge and Frank Wyatt, some of it exhausting and painful, but the wrestling techniques exhibited were mimicries of violence that, were they genuine, would have been life threatening. All of the night's drama-the bitter rivalry, the expressions of agony, the gloating of victory and despondent rage of defeat, all of it—was a masterful charade, the product of a great deal of skill, training and experience of the illusionists. In this match in particular, wrestling's constructed nature was especially clear given the blatant, borderline ridiculous, events that took place. Had anyone truly believed that the referee had sustained a serious head injury, the night would have ended with a stretcher for him and a jail cell for Dexter. And yet we, as the audience, looked at a man lying on the ground feigning injury and, though we did not touch him, pleaded with him to come to his senses and witness the foul play at hand. If crowd members held a sense of detachment towards the match, it was not to be found in their own performed reactions to the wrestlers. And considering my own affected response, I began to question the dissociation that I assumed to exist in my own mind. In pretending to 
accept these events as genuine, even as I assumed their falsehood, I began to believe, at least within the context established by myself, my peers in the crowd, and the wrestlers in the ring.

That professional wrestling is a "fake" was something that I assumed to understand long before I even considered watching a match, and this understanding was only confirmed as I prepared to undertake this research. But in "being there," experiencing wrestling — and thus, I believe, doing wrestling - I come to the goal of this thesis: to question the assumption that professional wrestling, and any other mode of performance, can be considered as anything but real. Wrestling, as a performance mode, does not suspend itself from reality. Instead, its enactors deliberately play at the surfaces of an assumed reality, and in doing so established an order for itself between the concrete and the phantasmic (Allison 2000). Wrestling is a lie, but it is a beautiful lie that its fans are all too willing to indulge. And in doing so we too become liars, and find this transformation exhilarating, unifying, and "real."

Professional wrestling is a nigh-inescapable force in contemporary American popular culture, and has been at least since the early 1980's. As a child, my deliberate disinterest in professional wrestling did not keep me from encountering it. Wrestlers sneered at me from tshirts worn by other kids at school, they lined the toy aisles and filled magazines and television commercials advertising whatever they got their hands on. I was well aware of the WWF (World Wrestling Federation), WCW (World Championship Wrestling), and ECW (Extreme Championship Wrestling), and the fighters on their rosters, even though I had never watched a single match. As an adult, my early distaste turned into an absurd and unexplained fascination, and I now see that the "adult world" is similarly inundated with snarling visages and musclebound warriors. Professional wrestling has not forgotten its child audience demographic —in 2014, Scooby-Doo and company teamed up with the wrestlers of the WWE to solve mysteries at 
WrestleMania in a direct-to-video cartoon film. Although the characters have changed, the gist of professional wrestling's performance has essentially remained intact throughout the years: bombastic personalities, colorful costumes, overwrought and often hilarious scenarios that necessarily end in violence in-and-out of the ring.

As these actors leave the ring, they further establish their presence in our public consciousness. Some go on to successful careers as film actors; Dwayne "The Rock" Johnson, one of the most iconic wrestlers of the 90's era, was recently listed as the highest paid actor in Hollywood. Others recount their lives behind-the-scenes in best-selling autobiographies. Some within the wrestling world have eschewed traditional celebrity for the "higher calling" of public office, exemplified by the election of Jesse "The Body" Ventura to the office of Minnesota State Governor in 1999 and the more recent, albeit unsuccessful, U.S. Senate campaigns of Linda McMahon (wife of Vince McMahon, CEO of professional wrestling's most successful franchise, the WWE). Unfortunately, the fates of too many former wrestlers are far less glamorous, finding life after wrestling to be filled with poverty, addiction, abuse, and a short end; many of the wrestling icons from the 1980's—Macho Man Randy Savage, The Ultimate Warrior, Rowdy Roddy Piper, among others - have passed away in their late fifties, their short lives attributed to the "rock-and-roll" lifestyles they experienced in their prime. Their stories, too, find a place as grim reminders of the perils of celebrity and the fleeting nature of success, and occasionally a condemnation of a business that takes too much from even its most celebrated figures.

Despite its effective permeation, professional wrestling's reception is markedly ambivalent. There is no question to its success as both a cultural form and a commercial enterprise — professional wrestling's most successful venture, World Wrestling Entertainment, Inc (more commonly known as the WWE), is a multi-million dollar enterprise that reaches 
markets around the world - but this success is often countered with a public disapproval and revilement. Professional wrestling is often typed as an "essentially" American form, but in this case "American" operates as an ironic descriptor for over the top spectacle as well as violence, xenophobia, racial discrimination, and sexism.

There are many critics of professional wrestling, and they don't hesitate to express their opinions; a great way to hear these responses is to simply mention that you are interested in studying the topic. For them, wrestling is brutish and barbaric, flamboyant, crude, and generally to be laughed at. One opinion that I hear frequently, which is mirrored in several academic texts on the subject, is that wrestling is a "soap opera for men": cheap, melodramatic pablum meant to cater to the escapist fantasies of the "unrefined masses." Expressing even a passing interest, let alone an enjoyment, in such diversion is to invite a similar evaluation of one's self.

In one case, I was with friends at a bar that was showing a rerun of WWE Raw program on the television. The middle-aged men in business suits that sat next to us were generally bemused at the sight. Smirking, one asked to nobody in particular, "Seriously, who is stupid enough to watch this crap?" I didn't have the heart to tell him that I was stupid enough to do such a thing. (So were they, apparently, as they watched continuously for the duration of their stay.) I encountered "covert" wrestling fans, those individuals (both students and professors, not to mention a few individuals whose work I had admired and attempted to engage with) who would approach me after I had given a lecture on my research at conferences and classes. The older people would, without fail, recount earlier tales of being dragged to wrestling matches and being fascinated at what they saw. Those closer to my age were more direct in their excitement, asking me question after question (sometimes in a hushed tone) about what I thought about a specific match, wrestlers, promotions, etc. I must admit, I often feel that this research is initially viewed 
as a quaint curiosity; only after it has been adequately deposed as a topic worthy of the vaunted halls of academia can people safely reveal their own personal interests.

In short, I believe that professional wrestling presents an interesting contradiction as an object of consumption, especially among the middle class. On the surface, you see wrestling dismissed as an entertainment form; but from my own (admittedly limited) experience, far more people understand — and even enjoy, to some extent—wrestling than would confess to the fact. But consumption of wrestling is something done covertly and privately, and is an unfit topic for public discourse. If an enjoyment of wrestling is to be shared, it must be done with others who are explicitly confirmed to be receptive. In other words, we discuss wrestling as we would pornography: either we overstate our personal detachment by presenting wrestling strictly as an object of critique, or we don't discuss it at all. Of all the forms of entertainment that we do permit, why does professional wrestling — violent and ostentatious though it may be, as are many other things we happily consume-border on the obscene?

Surprisingly, professional wrestling's most damning critique doesn't come from its content, but rather in that it pretends to be something that it isn't. On its surface, the world of wrestling is structured as if it were any other competitive sport: there are championship tournaments titles, a ranked roster for athletes based on their competitive results, rules and regulations, etc. The great "secret" in wrestling — which everyone seems to know—is that this is all a facade. A common refrain amongst those who are more sympathetic is that "outcomes are predetermined" in wrestling matches (de Garis 2005; Mazer 1998). In short, when two wrestlers enter the ring, both know well in advance who will be walking out as the victor. What is presented as a competition is, in fact, collaboration: a skillful, improvised performance of a physical narrative that is meant to take the audience from the starting bell to the referee's final 
call in a manner that is both enjoyable to watch and, to a certain extent, "believable" (de Garis 2005).

The public secret of professional wrestling is called kayfabe, a unique term in the professional wrestling industry that describes the attempt of actors within a wrestling promotion to present their actions as "true" or "real." In a sense, kayfabe undergirds every behavior within the frame of a wrestling performance. It defines both the pantomime of conflict within a match and those actions that contextualize the struggle; when wrestlers challenge one another to a match, or form an allegiance, or mock the crowd, they uphold kayfabe through their actions. Kayfabe is also maintained by the wrestling's other characters, as when the referee "misses" an illegal move by a villainous wrestler or, as in our example, feigns injury from a wrestler's assault. But kayfabe is not just the obligation of wrestling's actors, explicitly defined, it is a performance of the audience as well. On the night I described above, as we sat around the ring, cheering for our hero and insulting the villain, allowing the referee to lie unconscious, choosing to act as if we believed these things were real, were we not also agents of kayfabe? Or, in other words, were we not also acting as performers, constructing some part of the wrestling drama itself, with full awareness that our actions were "not real"?

For those who enjoy wrestling, kayfabe lies at the core of the entire practice and purpose of wrestling (Mazer 1998); without the planning of match outcomes, there would be no building of dramatic tension, no formation of protagonists or establishment of conflict, no story. For wrestling's detractors, on the other hand, this is enough to brand the entire enterprise as "fake." What is unusual is that such fakery is not scrutinized, and is in fact celebrated, in other contexts. When watching a science fiction or fantasy film, we don't consider the presentation of superhuman feats or otherworldly scenes as audacious. Nor do we mock the stage actor for his 
portrayal of a medieval king. Within their respective frames, these fictions are considered seriously and without irony, and indeed we want these fictions to be as "real' as possible. We applaud an actor's skill and dedication to their craft when they lose themselves in their performances, when their characters become as human as the audience members themselves. We also permit the breaking of the "fourth wall", where the illusions of stage and screen threaten to recognize the audience or expose themselves as fantasies. This may be regarded as little more than a charming novelty, but in certain performances, especially in modernist and post-modernist traditions, it can be regarded as transgressive, challenging, and brave. While professional wrestling fits into these standards, wrestling fans are apparently not afforded the luxury of suspension of disbelief; they are either gullible (or stupid) enough to be manipulated into accepting a fake, or too cynical to care if it's real or not. It seems unusual, for the outsider, for a wrestling fan to commit so passionately and authentically to a performance that they should know is fake.

I argue that professional wrestling is a unique, and also marginalized, genre of performance because it challenges the very definition of what a performance is. We think of performances in terms of their boundaries — discrete, explicit, and rigid separations of space, time, and contextualized behavior that displace their practice from daily life (George 1989; Remshardt 2004). As we establish these boundaries, we also form a distance between the "real" experience of the audience and the spectacle on display. Due to this distance, there is an assumption of a certain "safety" in performance; that actions or conveyed ideas that might be offensive or transgressive to the audience have some terminating quality, a line that will not be crossed. In professional wrestling, within the environments that I experienced it, this distance between performer and audience is kept at a minimum. While these boundaries are seemingly 
established within the context of a wrestling event, any assumption of "safety" - including, in a very literal sense, one's physical safety — by an audience member is short lived as these physical and social boundaries are demolished. The "doing" of professional wrestling amongst its practitioners includes what I have come to define as boundary play, deliberate strategies and actions that establish performative boundaries in order to subsequently enact a transgression. This creates an ever-present sense of ambiguity, and the individual cannot engage in a total suspension of disbelief: what is "fake" in wrestling may be real, what is real may be fake, and to a certain extent these definitions begin to lose their meaning. Through boundary play, the performative frame of professional wrestling takes on a liminality, wherein the objective reality of the audience and the performed fantasy become forcibly merged. It is only within this liminality that the emotionally transformative work of wrestling — communitas, perhaps — can take place (Turner 1964).

As I attempt to understand wrestling as a practice, I have come to reconsider the concept of kayfabe itself. While this is a term that is nearly-universally applied only to wrestling, I propose that we consider it within an "anthropological" context. Kayfabe should not be seen as just a veil of secrecy upheld by wrestlers or a wall that separates those in-the-know from those left guessing. Instead, we can consider kayfabe as the mutual practice that defines the social relationships within a wrestling community. In other words, it is a "contract," an obligation amongst both performers and audience to uphold the "reality" of wrestling within the context that it is performed. As in any set of relationships, there is constant negotiation between the actors in this community, varying degrees of power and control, and dominant modes of behavior that establish "normality" within the frame. Through kayfabe, wrestling behavior is extended beyond the context of the performative event. When fans comment on a promotion's social media to call 
a wrestler a dirty cheat - in other words, when they persist to perform in a way that suggests that a wrestler's actions are legitimate - they uphold kayfabe beyond explicit wrestling spaces. At the same time, they may choose to disregard kayfabe, and instead discuss wrestling outside of its performative frame. 


\section{CHAPTER II: "PERFECT BASTARDS"}

\section{A Brief History of American Wrestling}

Professional wrestling, in its current form, has its origins in the post-Civil War period of American history. As wrestling became a staple of developing collegiate sports programs, it also found popularity amongst returning Union veterans as a betting game, played in the pubs and taverns of east coast cities. The champions of these barroom brawls, seeking to test their strength against worthy opponents, would take themselves on tour, eventually becoming a staple exhibit of travelling carnivals and road shows. In these spectacles, professional wrestling inherited one of its most definitive attributes - the set up. In carnival venues, wrestling became a con, a fixed match meant to dupe the crowd out of their betting money. At these shows, a physically imposing wrestler would be revealed to the audience, alongside calls from the barker for anyone in the crowd to test their strength against him. Without fail, a decidedly-less-imposing person from the crowd would step forward. Though all bets were against him, our hometown hero would — without fail—secure a victory against the Goliath set out before him (Morton and O'Brien 1985). It wasn't a particularly clever con, and could only be attempted so many times before crowds would catch on, but the fundamentals of professional wrestling were established from these carnival standards: the stage names, the larger than life personalities and scenarios, the flamboyant costumes. The industry jargon of professional wrestling directly derives from its history as a carnival game; kayfabe, a seemingly nonsensical term referring specifically to wrestling's fictive elements, is in actuality a pig latinization of the word fake (Kerrick 1980).

With the rise of broadcast television as a popular and accessible leisure form, professional wrestling would abandon its carnival roots for more stable audiences (Morton and O'Brien 1985). But while bets no longer needed to be fixed in the house's favor, the fixing of 
matches - the "great lie" of wrestling — had become a staple of the medium. It is also, perhaps, one of its greatest credits. Any sport has a capability to tell a greater story about the society it represents. But the outcome of a legitimate game, though it can allude to some greater narrative meaning in retrospect, cannot fit some determined plot. By choosing in advance who wins and who loses, the organizers of professional wrestling fix its narrative. Characters and motivations can be established, conflicts ignited, and arcs traversed. Wrestling becomes a drama, and in some cases, a drama that can expand and evolve continuously over decades.

It is these dramas which have drawn the interest of scholars and critics over the course of wrestling's history. As a cultural form, wrestling begs a question of its categorization: is it a sport, or theatre, or something else entirely (Mazer 1998; Levi 2008)? This ambiguity

characterizes its consideration as an academic subject; for some scholars it is a popular television show (Soulliere 2006), for others it is a deeply personal and ritualized experience (Hill 2015).

But at its heart, professional wrestling is a cultural performance, and as such it "enacts the values of its particular culture" (Schechner 2002:30). And what wrestling says about its performers, its participants, and its particular culture, has been the driving question of all these examinations.

\section{Wrestling and Ritual Theatre}

French semiotician Roland Barthes was arguably the first to approach wrestling with serious critical inquiry. "The World of Wrestling," from his seminal work Mythologies (1972[1957]), is nearly universally cited in wrestling scholarship. And upon reading it, it is easy to see why; at the risk of compromising objectivity, it is an aesthetically beautiful piece. His description of hot floodlights, bustling crowds, and staged brutality gives that sense of "being there" that the ethnographer strives for. And he presents wrestling with undeniable poetic irony, seeing in it "a grandiloquence that must have been that of ancient theatres" (Barthes 1972[1957]: 
15) and likening wrestlers in the ring to divine beings, holding "the key which opens Nature, the pure gesture which separates Good from Evil..." (25). Beyond these poetic attributes, Barthes sees and celebrates professional wrestling as the true inheritor of a "primeval" theatre, tracing back to Ancient Greece in spirit if not in form. At its core, wrestling is a morality play, a struggle between good and evil that transmits its meaning in a way that legitimate sport performances cannot. The wrestling performance highlights a building sense of injustice, as the villain in the drama is allowed to elude just punishment. These scenes of justice thwarted build frustration in the audience, until this agony reaches a fever pitch and the hero reverses the narrative, finally allowing justice to be established. For Barthes, wrestling is not just entertainment or spectacle; it operates almost as a religious rite, framed on a society's understanding of morality.

This prescription of wrestling as a ritual form, with elements more akin to Western theatre (Craven and Mosely 1972) than sport performance, would be maintained by other scholars (Ball 1990; Migliore 1993) who sought to examine how wrestling performances ritualized contemporary conflicts in American society. Sociologist Thomas Henricks (1974), drawing on the structuralism of Claude Lévi-Strauss, further developed an understanding of how good and evil are presented through the construction of wrestling's characters. For Henricks, good and evil are ultimately matters of identity; heroic characters are defined by their association with the values, beliefs, and identities of an audience, while villains are defined by opposition. Furthermore, Henricks would propose that in wrestling, justice ultimately resides in the individuals will to act, as societal systems of law and order (here represented by the rules and regulations of the wrestling sport) are unable to govern competently. It is important to note that for both Barthes and Henricks, the core of wrestling's drama truly resides in its representation of evil; Barthes describes the "bastard" as "the key concept of any wrestling match" 
(1972[1957]:17). It is the villain's actions that move the drama forward and create a motivation for the hero to act in the name of justice (and ultimately, to the crowd's affirmation). And in analysis, it is also the villain that stands out as something "abnormal," as a representation of some greater societal foe.

Anthropologists of performance have largely been concerned with understanding how performance events (rituals, ceremonies, spectacles, etc.) produce social meaning for their participants through the presentation of symbols and meaningful behaviors (Korom 2013). Exemplified by the works of Victor Turner (1967, 1986), early performance anthropology focused on cultural performances as texts dictated by larger structural symbolic relations in a society. Later theories would instead argue that social meaning arises from a performance's "emergent" quality (Bauman 1977; Lord 2000[1960]; Bauman and Briggs 1990), where a performance event's particular positioning of audience and performer(s) gives rise to a unique experience. Under this view, all participants in a performance interact and collaborate to construct a reality that becomes visible through symbolic speech and signifying action (Schieffelin 1985, 1997). Performance studies, a sister discipline to performance anthropology, combines a focus on ethnographic analysis and cross-cultural comparison with standing methodologies in the study of theatrical performance and dramaturgy (Schechner 2002).

As a performance genre, professional wrestling can be defined as a liminoid form. Drawing on the work of Arnold van Gennep (2010[1960]), Victor Turner proposed that the notion of liminality, of being "betwixt and between" structural categories, is an integral part of the ritual life of a society $(1969 ; 1987)$. Certain liminal rites - the rite of passage being the classic example - operate to recognize and resolve categorical crises, when individuals move between defined and understood social roles (1987). Liminoid forms - including spectacle 
performances like concerts, theatrical performances, and wrestling matches-do not operate to solve crises but share important features of liminal rites (1974). Among these is the experience of communitas, an "anti-structural" phenomenon wherein participants in a rite share an equality that transcends social roles $(1969 ; 1987)$.

Another important feature of the wrestling performance is its presentation of the human body and its behaviors as a dominant symbol. Wrestling displays a diverse array of bodies of different sizes and shapes, and within the moral drama of wrestling there exists the possibility of ascribing morality to physical forms. Consider Barthes again, in his description of a wrestler who "displays in his flesh the characters of baseness...not only is his ugliness used here in order to signify baseness, but in addition ugliness is wholly gathered into a particularly repulsive quality of matter...so that the passionate condemnation of the crowd no longer stems from its judgment, but instead form the very depths of its humours" (Barthes 1972[1957]:17).

The very act of being in a society constitutes a form of cultural performance, with scholars recognizing human bodies and their actions as cultural constructs with their own sets of classifications and categories (Mauss 1973[1935]; Turner 1993[1980]; Farquhar and Lock 2007). A wide body of research is devoted to examining the ways in which bodies enact social meaning and are acted upon by larger societal and cultural structures. More specific theories of bodily movement and practice have been developed to recognize physical vocabularies as parts of larger systems; while these theories have been most readily applied to dance and ritual performance (Farnell 1995), they have also been used to frame sport performance as an embodied practice (Dyck and Archetti 2003). Framed around spectacular presentations of the body, the wrestling drama provides interpretations of physique and actions which correspond to the larger moral structure of the event. 
Wrestling performance also involves the "selling" of emotions and reactions, particularly pain, in order to elicit visceral responses from the audience and to create a logical physical narrative (De Garis 2005). The representation of pain and suffering is of particular importance in professional wrestling (Smith 2008). Scenes of suffering are intense experiences for audiences, who "experience" the pain that performers display (Schulze 2013) and are compelled to engage with the drama at hand. The body subjected to aggrandized displays of violence is also an aspect of grotesque realism (Bakhtin 1984[1965]; Remshardt 2004; Brottman 2005), a narrative trope that symbolizes societal order with the human body, which is profaned, violated, and transformed as a form of social critique (Stallybrass and White 1986).

\section{Professional Wrestling as Mass Media}

Although wrestling has always had a live audience, it is a performance form that has been shaped by the structure and requirements of television broadcasting (Beard and Heppen 2012). Even in small-scale wrestling productions, which may be recorded but are not broadcast live, one can still find these features. Since the mid-20th century, professional wrestling has been a staple in television markets. In the early days of broadcast television, wrestling promotion "territories" were defined geographically by the broadcasting areas of local television stations. Since the 1980 's, with the rise of the World Wrestling Federation (WWF) as the premiere American wrestling promotion, wrestling has enjoyed widespread success and international audiences as a televised performance; it is safe to say that most people experience professional wrestling from their own homes, and not in a live setting. In this environment, the WWF-now known as World Wrestling Entertainment, or WWE—-holds an effective monopoly on nationally televised wrestling programming. For most scholars studying wrestling as a mass media form, professional wrestling is synonymous with the format, style, and stories of the WWE. 
A relatively recent development of the last 25 years, media anthropology examines the ways in which communities, networks, and relationships are impacted (or formed) through the deployment of mass media technologies and their products. As these technologies and means of distribution become more accessible, marginalized groups and niche communities have made use of them as a means of advocacy and awareness both within communities and in larger public spheres (Ginsburg et al. 2002). On the other end of the spectrum, the interest of nation-states in the creation and regulation of media content has also lead researchers to examine the ways that media forms "play crucial roles in producing nations and shaping national imaginaries" (Ginsburg et al. 2002:11); these roles become unavoidable in discussions of censorship and the definition of obscene or dangerous content (Mazzarella 2013). While the presentation of cultural norms in televised professional wrestling has been studied (Jenkins 2005[1997]; Soulliere 2006), a common theme in this prior research is its lack of engagement with wrestling audiences and viewers.

Audience ethnography, which frames viewer perceptions within a larger system of social context and economic networks, is a methodology specifically poised to examine how audience interpretations reflect (or oppose) the goals and assumptions of media producers (Murphy 1999; La Pastina 2005; Pace and Hinote 2013). Furthermore, as wrestling has had a long history of televised broadcasting (Morton and O'Brien 1985), it has been proposed that the style and structure of American wrestling performance has been fundamentally shaped by the demands and necessities of television formats (Levi 2008). As most of the matches I am observing are recorded for distribution purposes (either commercially or by fans), the role of the camera in the formation of live performances must also be considered even when these events are not intended to reach national network audiences (Beard and Heppen 2012). 
Content analyses of WWE programming have typically focused on wrestling as a mass media form with the power to encode and impart problematic normative statements concerning race (Campbell 1996; Serrato 2005; Taylor 2014), nationality (Mondak 1989), gender, and sexuality (Jenkins 2005[1997]; Soulliere 2006) to its viewers. Jeffery Mondak, looking at professional wrestling as a nationalist drama, argues that wrestling popularity flourishes in times of diplomatic and societal tension (1989). Society's villains, here literally being the ideological and economic rivals of the United States (Campbell 1996) are represented as cartoonish ethnic and nationalist stereotypes that fit to the political landscape of the times. Brendan Maguire (2005) furthers this argument by suggesting that political incorrectness is one of the prominent features that draw fans to wrestling, with wrestling dramas highlighting concerns about social tensions and the potential threats to the status quo. Equally prominent is wrestling's representations of masculinity; Henry Jenkins III (2005[1997]) likens professional wrestling to daytime soap operas, a serialized narrative form catered to working-class white men that emphasizes aggression and heteronormativity as masculine ideals. Further examining the connection between violence and manhood, Danielle Soulliere (2006) argues that WWE wrestling defines ideal masculinity through the willingness to commit violent acts and to respond to conflict primarily through aggression. Focusing more specifically on wrestling masculinity's connections to sexuality and femininity, Sharon Mazer (1998) proposes that professional wrestling does not support a normative or idealized concept of masculinity, but rather stages masculinity through a diverse set of performances that are ultimately defined as "not feminine." Furthermore, Mazer more closely examines the role that women play in the wrestling of her time, arguing that wrestling performances have an inherent homoerotic nature, which is 
presented as heteronormative when played out by men but is emphasized as erotic when women enter the ring.

\section{Wrestling as Live Performance}

These criticisms of professional wrestling are certainly valid. However, they are also grounded on a narrow depiction of professional wrestling as presented by one promotion and during a certain period of time. The vast majority of contemporary and recent wrestling scholarship is expressly devoted to studying wrestling in the WWE; while the WWE establishes standards that are mimicked and followed by other wrestling promotions, these standards are also challenged and subverted by the numerous producers of independent professional wrestling that are active in the present day. In my fieldwork, I have seen examples that align with these dominant conventions and hegemonic narratives described above, but I have also seen a variety of situations that require a different perspective. Furthermore, much of the literature on professional wrestling dates from the late 80's and early 90's, when WWE wrestling was becoming a serious and prominent force in American popular culture. Contemporary professional wrestling has, in some aspects, deviated greatly from what was commonplace in this "golden age" of wrestling, and in some regards the medium has responded to these critiques of representation. While I would personally say that the WWE has a long way to go if it wishes to deal with its problematic attributes, it has also come a long way since its inception.

This scholarship has also largely ignored the role that audiences play both in the construction of wrestling performances and in the reception of wrestling content. Content analyses of WWE productions confine wrestling to being a television show, with every aspect of the performance being scripted and controlled before it is brought before an audience. But professional wrestling has a tradition of improvisation and audience interaction which is not 
wholly represented by what reaches television screens. Wrestling audiences are also diverse groups, not just representing the assumed target demographic of working-class men, and they bring unique perspectives and interpretations into their spectatorship. Eschewing the audience in media analysis rejects the personal subjectivity of the viewer, and eliminates their ability to reject some parts of a message while retaining others. The "general" wrestling fan that I have met in the field may follow the WWE, as well as a multitude of other wrestling producers, but does so with their own set of reservations and concerns: they may love a medium even though they may not agree with its message.

Compared to analyses of wrestling as media, ethnographic studies of professional wrestling are few and far between. Sharon Mazer (1998) and Heather Levi (2008) have both done exemplary work with their extended fieldwork amongst professional wrestling training gyms in the United States and Mexico, respectively. In both, we see wrestling training as seamlessly combining education in physical technique with development of wrestling personas and establishing rapport with an audience. At its most basic and technical level, professional wrestling represents a collaboration between performers and audience members. But while both Mazer and Levi spent some time amongst the crowds at wrestling events, the audience community takes second stage to the wrestlers in these scholars' studies. Of the ethnographic work on wrestling thus far, Annette Hill (2014) provides the clearest and most direct description of the fans that attend these events. Reading Hill's analysis of wrestling audiences, it is easy to see why scholars are quick to define the practice as ritualistic; here, wrestling is almost an ecstatic practice, with wrestlers acting as the maestros of the emotional cadence of the event and audiences willingly allowing themselves to be consumed by the performance. 
My decision to focus on small-scale professional wrestling offered at live, local venues was based on two primary points. First, I hope to provide a greater understanding of a complex and often misunderstood cultural practice and its practitioners from a viewpoint which has been underrepresented in the standing literature. Second, I wanted to understand an aspect of my community which, up until now, has operated mostly out of my perception. These events are truly community events: they are attended by locals, and the wrestlers involved are often performing in or near their hometowns. Independent wrestling promotions have the opportunity to tell their own stories that matter to these communities, and operate largely apart from the national promotions that dictate what wrestling is to the general public. In these venues, I believe we have the chance to see what wrestling could be, and how performers and audiences cooperate with one another to realize these aspirations. 


\section{CHAPTER III: BOUNDARY PLAY AND WRESTLING PERFORMANCES}

A dominant characterization of professional wrestling is as "spectacle." This notion appears almost everywhere in academic, fan-generated, and lay critic discussions alike. At first, this label makes sense: with its bombastic characters, over-the-top action, and ridiculous scenarios, wrestling is certainly "spectacular." Spectacle, however, implies a certain disassociation from its audience. Though a spectacle might overwhelm our senses and consume our attention, it remains an unapproachable fantasy, a distraction removed from our everyday, "real" experience. Wrestling, on the other hand, is a performance defined by its tangibility and, in fact, dependence on the "spectators," as I argue in this thesis.

To illustrate this point, I describe the first wrestling match I ever attended, at the beginning of my preliminary fieldwork when I had no idea of what I was getting into. I knew what professional wrestling was, but I wasn't a wrestling fan. I had never been to a wrestling match, nor had I really watched one on TV. And I certainly had no experience of local professional wrestling; in fact, I didn't know if it really existed or not until a day before making this trip. On the road to the venue, my biggest worry was that I was walking into some sort of joke, a mockery of the sort of wrestling that one sees on TV. Two things occurred that night that informed the entire course of my research. First, I quickly learned that professional wrestling is sort of a joke, and sort of isn't. It has the unique capability of being able to laugh at itself, but then take itself seriously under the most ridiculous of circumstances. In the second match of the night, the heel wrestler — the "bad guy"—was a bearded, half-mad wild man, clad in animal skins and swinging a club around. He ambled his way up to the ring, bumping into seated audience members and spitting insults at whoever caught his eye. As he crawled under the ropes to enter the ring, he fixed his attention on a man in a front row who was a little more persistent in 
returning the wild man's verbal abuse. (This man, too, was bearded. And I promise that this point is relevant.) Our wrestler had had enough of this, so he doubled back and jumps back over the ropes, in front of his target. With both hands, he took the fan by the throat and brought him eye to eye. "Yer just jealous o'me, cuz my beard's bigger than yours." An irritated referee, broke him off and pushed him back into the ring, but nobody in the crowd was alarmed at the apparent assault that had just taken place. Especially not me: I sit, confused and fascinated.

Later, I was standing outside during the 10-minute intermission between the third and fourth matches. I was trying my hardest to process the bizarre world that I was quickly being introduced to when a man who was seated close to me appeared. Smoking a cigarette, he asked if I'd "had more than I could handle" yet. I'd been identified as an outsider. (To be fair, I'd made it pretty easy; like any good novice ethnographer, I came in with my notebook and spent the matches trying to scribble down what I was seeing. One of the wrestlers noticed me, trying to hide away in the back row, and called me out on it.) I told him that I had recently become interested in local wrestling, and he recommended some places to check out. One venue, which I would later frequent, was doing a "fan appreciation month" and was putting on some good shows, he said. The wrestlers were good, the crowds were big, and "everybody is just a certain level of 'into it', you know?" I did not, in fact, know; so I asked him what he meant. He told me how, a week before, he got one of the wrestlers so worked up that, in the middle of a match, the wrestler picked up a trash can and threw it at him. He told me this with a smile on his face, and I realized that these interactions are ideal. They're supposed to happen.

As I became more familiar with the standard conventions of professional wrestling performance, I came to have greater appreciation for those matches where everyone is "a certain level of 'into it."'And while I've never been choked out by a wrestler or had something thrown at 
me directly, I have had plenty of first-hand experience of occasions where I have been unwittingly (but not necessarily unwillingly) dragged into the wrestling performance. I believe that wrestling is, at its core, is an exercise in carefully managed chaos, and there are fevered points within a match where wrestling becomes more than just the physical act of wrestling. It entails a necessary engagement with the audience, and with this engagement comes a degree of risk and a responsibility for audience members to conduct themselves in an appropriate manner. This sort of interaction is not a mistake, nor is it uncommon. It is something relished and sought out by wrestling fans; here we begin to see the proper level of "into it" that a wrestling match should convey.

In this chapter, I discuss what it means for wrestlers and wrestling fans to "get into it." More specifically, I want to detail the performative strategies that professional wrestlers undertake to engage with a wrestling audience, and how a wrestling audience performs for the wrestlers in kind. In doing so I use concept of boundary play, the deliberate means by which a performance's constructors break the rules that they apparently set out for themselves and their audience. Through boundary play, the successful negotiation between the two parties of performer and audience that serves to weaken the barriers that we come to expect in the Western theatrical tradition. Boundary play allows a performance to become "real," to begin to free itself from the suspension of disbelief. In a sense, this is an analysis of wrestling as "theatre"; however, I propose that wrestling, in its performance, necessarily becomes a social practice that emphasizes the ritual purposes of performance art.

Because the outcome of professional wrestling match is pre-determined, the actual wrestling on display, which appears to be an athletic competition, is in actuality a collaboration between performers that is mostly improvised on the spot. Because match outcomes are 
controlled in this way, promotions can establish narratives based on how wrestlers fare in their matches. These characters are given a goal (winning a championship title, or a match against a rival, etc.) and are presented with conflicts that require them to adapt to their situations - the essence of any narrative drama. A wrestling event, then, acts as an "episode" that serves to continue the storylines of the promotion's characters. In some cases, especially in WWE wrestling, an individual wrestler's character may be continuously developed over decades. The fiction of wrestling, kayfabe, is a performative practice established by the wrestlers and other characters in a promotion but also followed and sustained sustained by an audience's actions. For example, wrestling characters are defined as heroes and villains (faces and heels, respectively, in wrestling terminology) by their storylines and behavior in the ring. Audiences treat these characters accordingly, cheering and for face characters and booing, mocking, and insulting the heels. One of the key attributes of a successful wrestler is to evoke a strong and appropriate emotional response from the audience through their verbal and bodily performances.

In lieu of providing a formal definition of boundary play, which I will return to later, I will first describe it as the behavioral process that I experienced in the course of my fieldwork. In the context of a performance, boundary play presents as a delineation and subsequent transgression of the supposed boundaries that outline the disparate social roles of performer and audience. In other words, boundary play occurs when the constructors of a performance set out rules for the express purpose of breaking them. The boundaries here- both literal, physical separations and the rules or mores governing appropriate interactional behavior-may be explicitly established, through speech or writing, in the duration of a performance, or they may be implicit, part of a social standard that audiences come to expect. By "performance," I generally recognize the myriad forms of social activities wherein there is "[an] assumption of 
responsibility to an audience for a display of communicative skill" (Baumann 1986:3). Any performative context can provide the possible grounds for boundary play. But for our express purposes here, I'm particularly concerned with "artistic performances": stage plays, music and spoken-word recitals, dance ensembles, etc., which are colloquially defined as "performances" in our society and are generally regarded as being mediums for aesthetic, emotional, and thematic expression. In a Western context, these sorts of performances are enacted subject to an established field of traditions and standards, which have developed socially and historically over the span of centuries in one form or other (Schechner 2002). In theatre, as well as at a wrestling match, performers and audiences are clearly and distinctly defined and the performance itself adheres to discrete constraints of space and time. It is here, where these boundaries are most visible, where boundary play can be clearly experienced.

The concept of boundary play was initially established in an eponymous article by Christena Nippert-Eng, wherein she defines the practice as "the visible, imaginative manipulation of shared cultural-cognitive categories for the purposes of amusement" (2005:302). Boundary play here relies on the participants' socially-constructed cognitive awareness of the boundaries between interrelated but mutually distinct categories. By recognizing these divisions, and then transgressing them, a new social environment is created that necessarily refers to the previously established order, thus contributing to the participants' amusement (304). However, this process is always marked with some degree of risk as participants knowingly subvert behavior and norms that they regard as proper. This risk could be merely slight social embarrassment, or may provoke long-term and severe consequences depending on the boundaries being subverted and the seriousness of the play $(306,308)$. Thus, those engaging in 
boundary play must have shared expectations of where a dividing line is drawn and how far it should be pushed.

The examples that Nippert-Eng provides are all spatial, even architectural, though she recognizes that boundary play may take on other forms and that spatial relationships come with corresponding social ones. When children crawl into a dog crate and fasten it shut, while their dog looks on from the outside, they play at the separations between humans and animals, pets and owners, etc. When the younger children further this play, by barking and wanting to drink water from a bowl on the ground, their older siblings dismiss it as being too strange, ducking out as the boundary play is pushed too far (303-305). In a more formal example, an exhibit at an aquarium features a massive tank full of large and exotic fish, taking up an entire wall of the viewing room. The concave glass wall reaches above and around the viewers, as if to trick them into thinking that they are submersed as well (307). For Nippert-Eng, these playful constructions of space can bring people to re-think mundane activities or social mores in a profound manner: boundary play can become boundary "work," a longer-lasting and significant evaluation of the separations that we produce throughout our social lives $(316,319)$.

I follow the foundation that Nippert-Eng established, but focus here on a particularly salient categorical pair in professional wrestling ("performer-audience") and elaborate on its presentation in this context. However, in extending boundary play to include the performative practices including and beyond the spatial, my formulation of the concept differs from NippertEng in some fundamental ways. The first difference is the Nippert-Eng's notion that all boundary play is enacted for the purposes of amusement. Boundary play in professional wrestling is enjoyable for audiences, and this is probably true for the performers as well. For wrestlers, however, these practices are part of the necessary emotional labor that their performative role 
dictates. In other words, playing with boundaries is part of their "job description." Boundary play may not necessarily be enjoyable for all parties as well. Consider the aquarium example that Nippert-Eng outlines above: I have actually visited the exhibit that she describes, both as a child and in more recent years. While I can appreciate the captivating effect of this space's construction now, my first experience of this place also reminds me of its capacity to overwhelm and terrify. Boundary play in professional wrestling, and in other theatrical examples (which will be discussed further), may be employed to frighten, shock, or unsettle an audience, to remove them from their comfort zone in order to reach some further goal.

I also disagree with Nippert-Eng in her prescription that boundary play requires an agreement between participants in their "wish to use [a] boundary as the source or focal point of their amusement" (Nippert-Eng 2005: 304). In a performance environment, the performers exercise some power in their ability to dictate how and when boundaries should be pushed. As a party to these performances in the course of my fieldwork, my early introductions to the standard boundary play in wrestling were wholly unanticipated. Learning how to react in situations where performative boundaries were subverted required some willingness on my part to adapt to the circumstances of the performance; by sitting in the crowd, I was susceptible to being called out or made fun of by wrestlers and I was expected to dodging things (or people) being thrown in my general direction. While I or any other audience member was always free to leave the performance space, being a spectator required dealing with some behavior that may not necessarily be agreed upon. For a novice spectator, this is surprising and at least a little offputting. Only after becoming more familiar with the "rules" of this performance did I come to realize that this was part of the fun. 
Perhaps our diversions on these points come from differing definitions of "play." Nippert-Eng adopts a standard definition of play as "activity engaged in for enjoyment or recreation" (Nippert-Eng 2005: 319). This is a practical term, utilized equivalently in a sociological context and in practical usage. Within anthropology, this conceptualization is problematized (Malaby 2009). Noting that play has been a historically understudied phenomenon, anthropologists have recently given it fruitful scrutiny. Malaby and Nippert-Eng note that play should not denote a categorization of activities, but rather an approach that renders any possible activity as "playlike" (Malaby 2009: 205; Nippert-Eng 2005: 315). To play is to render an activity's outcome to some degree of chance; a desired outcome may be approached through skill in the "game" at hand, but is ultimately a matter of contingency. Contingency in play allows for possibilities of innovation, production, and control. At the same time, it also comes with a certain threat of undesired outcomes. This is necessary: the dodging of risk in the pursuit of reward is what makes play "fun." But it also requires societies to restrict play, to keep it bounded in certain spaces (both physical and temporal), as the necessities of daily life require the certainty of a controlled and ordered setting (Nippert-Eng 2005:308). But I do not believe that this introduction of chance is necessarily for enjoyment. Play may be taken up out of necessity, or compulsion, or for any range of reasons beyond the individual's enjoyment. For the professional wrestler, while it may end up being "fun," playing with the audience may also be a necessary activity to take up if one hopes to be a prominent and memorable character in the audience's mind. Both Malaby and Nippert-Eng question a work/play dichotomy by suggesting how work may become more playlike; but what is left relatively unexamined is how play can become like work. 
I understand boundary play as the introduction of contingency into a performance event, with the performance's boundaries being the source or focus of this introduction. By "boundary," I mean any sort of partition that orders a performance event. This is a deliberately broad definition: a boundary can be a literal, physical structure (or lack thereof) that separates performers and audiences, and it can also refer to the socially contextual rules and regulations that dictate how a performance is meant to be performed or observed. In a sense, both of these classes fulfill similar roles in the social ordering of a performance event. The "rules" of a performance are inscribed into the space that the performance inhabits; usage of certain spaces is subject to appropriate and inappropriate utilizations, which are meant to be understood by those who participate in the performance. In a standard classroom or lecture hall, for example, the players have learned their roles quite well through years of routine. Students occupy the aisles of cramped desks, each facing the wall which has been designated as the "front." A gap separates these rows from a larger desk, or a lectern, etc., where the instructor is put on display for his or her subordinates. To stand at the front is to be put in a performer's role, to speak or initiate activity; to sit opposite means to listen quietly, to only speak when called upon to do so, and to otherwise make no significant distractions. The power of this arrangement is such that this space is used equivalently even when it is not "acting" as a classroom. And then the space's physical composition might be manipulated so as to alter this social arrangement: desks may be put in a circle, to encourage discussion or to attempt to denote equivalence between the instructor and students. Whatever way this space is engaged with, the boundaries that compose it are informed by (and subsequently inform) the social processes that it hosts.

In the Western tradition of artistic performances, these boundaries are familiar and fundamental to the medium. We generally understand what a "stage" is, although it may take the 
form of a proscenium setup, a black-box, or some other improvised space. In each there is a performance space - which is populated by the characters, props, and activity that the dramatic fiction calls for-and the spectator's space which hosts the audience, as well as some of the crew whose performances of labor enable the artistic performance on display. The social structuring is quite similar to that of the classroom. Audience members receive the performance mostly passively, while the performers onstage interact with one another but rarely acknowledge the individuals observing their movements. The silence of the crowd is sacrosanct in performance; laughter and praise can only come at pre-ordained lulls and spaces between active moments, while negative feedback is strictly taboo. Actors learn to recognize where these breathing moments are necessary, and to weave them into their work. Beyond the routine processes of the performance, these separations further serve an important conceptual role. The layout of the theatre tells the audience when and how to believe certain things. The dominant boundary here, at the end of the stage, is so important in its physical non-existence that we have named it. The fourth wall, the invisible and ever-present division enclosing the stage, breaks the world into a performer's side and an audience's side. As audience members, we permit belief in things that occur onstage that we would otherwise reject as ridiculous. Actors, in their roles, can murder each other, practice magic, transform into beasts and be taken seriously in their doing so. Generally speaking, we praise performances that are so "real" that they further encourage us in our belief in the impossible. But when the performance reaches its final temporal boundarywhen the curtain falls and the house lights come back on—our suspension of disbelief is ended and the stage-space becomes reincorporated into the "real world." The crewmembers sweeping up afterwards are far less permitted to kill each other than their acting counterparts were beforehand. 
The conceptual and cognitive importance of the "fourth wall" in performance derives from this allowance for the suspension of disbelief. Theatre necessarily presents a problem for its audience in the division between the actions of characters and narratives being portrayed through performance and the "real" human beings acting alongside and through these characters-a problem that theatre scholar David George terms "ambiguity" (George 1989; Remshardt 2004). Ambiguity requires that fictive performances mark their falsehood and separation from daily life, so that "all performances create a here which is not 'here,' a now which is not 'now,' restlessly slicing time and space into layers of 'difference'" (George 1989:74). Nippert-Eng highlights an equivalent problem occurring through play: the ultimate social risk from those who play is the ambiguity in their actions and intentions, and so "play time" is produced as a distinct sectioning of time (and space) in order to constrain this risk to a particular social setting and social role for the players (Goffman 1961; Nippert-Eng 2004). Boundary play, then, is particularly dangerous (2004) and thrilling because it allows for a challenging of the fundamental boundaries of performance (George 1989). Through boundary play, the lines between the audience's reality and the reality constructed through performance is blurred. A typical audience member approaches a performance event with an understanding that it is "staged," and is willing to suspend their disbelief in accordance to the rules that they are familiar with. But as these rules are transgressed, they encounter the performance in very "real" ways, contrary to these expectations. This upsetting of the recognized order can be surprising, or even fearsome, for the audience member, who must now attempt to find the "new" social ordering of the performance and their presence within it.

Experimentation with these boundaries and the established roles of performer and audience is no stranger to the theatre: in as much as we have colloquially defined the fourth wall, 
so are we familiar with breaking it. In theatrical performance, breaking the fourth wall takes one of two general forms. Either it is an amusing novelty, a brief aside meant to rise a knowing chuckle from the audience; or it can inform the entire foundation of a theatrical work, the dramatic processes of the actors, and the purpose and presence of the theatrical narrative. In the latter case, performative boundary play is regarded as transgressive, revolutionary, and important. Playwrights who incorporated these practices into their works have been since regarded as formative, pushing the medium into novel arenas. Defining the concept of "alienation" (or Verfremdungseffekt) in acting theory, Bertold Brecht sought to introduce necessary separations between actors and the roles they were performing, thus transforming the interactional relationship between these actors and the audience (Schechner 2002). One of the goals for Brechtian theatre was to destroy the notion that the theatrical fiction played in a world of its own designing, emphasizing the ever-present and changing social context surrounding an individual performance. On the other end of the spectrum, Antonin Artaud's "theatre of cruelty" aims to produce a fiction so visceral and commanding that it consumes its audience, "spill[ing] into the spectatorial space — physical and sensual—until all difference is obliterated" (Remshardt 2004:28). (As a point of interest to the anthropologist, both Brecht and Artaud were moved to reconsider the structure of Western theatre following their introduction to non-Western theatrical forms.) Note that in the case of Artaudian theatre, the experimentation described is not only conceptual: it necessitates a redefinition of the physical and spatial orderings of the performative frame, with actors "reaching out" to meet their audiences in new and unfamiliar ways.

Beyond the theatrical avant garde, boundary play has also found a familiar home in a less lauded context, namely the cramped VFW halls, the unheated warehouses, and high school gymnasiums where professional wrestling is performed. The transgression of wrestling's own 
boundaries can't truly be considered experimental; since the early inception of wrestling as a popular form of entertainment, when villainous wrestlers had to be escorted to and from the ring by bodyguards so as to not face the wrath of enraged spectators (Morton and O'Brien 1985), boundary play has been a fundamental aspect of wrestling performance. In wrestling, we see elements of Artaudian "total theatre" (Remshardt 2004: 28) taken to extreme limits, with performers meeting the audience in ways that can entail both social risk and literal, physical harm to the audience's person. But despite wrestling's insistence in challenging traditional modes of performance and spectatorship, critical response outside of dedicated wrestling circles has yet to respond to this engagement. Artaudian theatre is visionary, while wrestling is "fake." There exists some key perceptual difference between the stage play and the wrestling match, allowing the former to be defined as "art" and the latter regarded only as an elaborate lie. And it seems that wrestling's capacity to challenge the basic social dynamics of the performative frame, and to allow for the possibility of innovative interactional experiences within its performance, that provides the basis for this derision.

I believe that this definition of "falsehood" is dependent on a variety of factors. It cannot be ignored that wrestling performances are subject to American class distinctions. While stage theatre takes a variety of forms and is available to a diverse range of audiences, it generally enjoys a reception as "high" art. Wrestling, though successful both financially and as an influence in popular culture, does not hold the same distinction; it is a "low" or "populist" performance form, generally regarded as entertainment designed for and consumed by the American working class (Jenkins 2005[1997]). Outside of the cultural milieu of the America working class, wrestling is thus considered distasteful (Bourdieu 1984). We may consider also the content of wrestling itself. While the performance of wrestling features interesting and 
dynamic social exchanges, the "text" of wrestling matches might be regarded as quite simple when taken at face value. Characters are motivated by a desire for fame or glory, they make alliances or betray one another, and come to blows over sleights and insults; ultimately, good triumphs over evil, and heroes are rewarded until a new set of challenges arises and the cycle begins anew. Due to the nature of the medium itself, especially in the small-scale wrestling promotions that I am familiar with (which do not feature long monologues or acted scenes which contextualize matches), the capacity for wrestling to tell complex stories with its characters is limited in the short term. Professional wrestling is also notorious for its violent and profane content. Considering that "wrestling," generally defined, is a sport involving two individuals putting each other into physical submission, and that professional wrestling specifically involves a class of characters defined by their capacity and willingness to cause suffering, there is an extent to which we must say that wrestling is necessarily a violent display, though the standards for what sort of violence is acceptable within a wrestling match has changed over time. Wrestling violence may further define it as a distasteful or unseemly practice, but stage theatre itself is no stranger to brutality and bloodshed. The perceptual difference here could be that violence in theatre is seen as working towards some larger narrative or thematic goal, while violence in wrestling is regarded as operating in operating in an exploitative or spectacular manner, existing for its own sake.

But professional wrestling, as a performance genre, is itself somewhat of an anomaly. Other scholars have described it as a fundamentally "liminal" form (Levi 2008), displaying attributes of many other social and performance forms - theatre, sport, ritual, dance, etc.-but not fitting neatly into any one specific category. Thus, a strict consideration of wrestling as theatre neglects a key characteristic of the medium: whereas theatre is defined by its separation 
of factual and fictive worlds (George 1989), in professional wrestling a neatly defined "fourth wall" simply doesn't exist. The agreement of performers and audience members to uphold kayfabe allows the wrestling fiction to be sustained the beyond the expected and necessary boundaries of theatrical performance. If wrestling does not attempt to follow the fundamental rules of theatrical performance, then to what extent can we say that wrestling operates within the same conceptual and aesthetic spaces of dramatic performance? Furthermore, consider the differences between the theatrical audience and the wrestling audience. The theatre attendee is expected to suspend his or her disbelief within certain constraints, and they do so mostly passively. This audience does not typically show joy or outrage as onstage events unfold. In wrestling, however, audiences are expected to hold up their end of the kayfabe bargain by specifically introducing this sort of emotional response into their spectatorship. Audience members themselves are actors in the wrestling fiction with their own roles to play; they cheer and boo at appropriate times because it's in their script, in some sense. And as wrestling fans "pretend" to believe in wrestling's staged action, it is very easy for authentic emotions to be produced. For the outside observer it must seem odd for a crowd to rant and rave at something that they know is "fake." But for fans it is the contrary: audience performances are the necessary basis through which a wrestling match becomes "real."

\section{The Boundaries of Wrestling Performance}

In any performance, boundary play is practiced on the identifiable and understood separations that structure the event. For wrestling, I identify these separations as the different sorts of rules, both spoken and unspoken, that are introduced in the context of a wrestling match. As expected, these rules are the apparent means by which a performance is identified as such, they further dictate appropriate behaviors for all parties involved. As boundary play occurs, these 
separations are transgressed, requiring performers and audiences to re-orient themselves to the new social structuring of the event. The major question for these apparent initial boundariesand I find this especially true in wrestling —is whether they were ever "rules" in the first place, or merely the illusion of order.

For professional wrestling, I have identified three categories of rules which are established and subsequently subverted as a match endures. First there are the structural boundaries, the actual rules and regulations that define what a wrestling match "is." (Or rather, what a legitimate match is supposed to be.) Then there are the spatial boundaries, the ordering and division of spaces that separates the actions and identities of performers and audience members. Finally, interactional boundaries outline appropriate behavior between performers and audience members as they interact with one another verbally and physically. As they are outlined here, these categories are listed according to the successive degree of risk that is entailed when boundary play is attempted in each: wrestling's structural boundaries are transgressed frequently and safely, to the extent that this is a core aspect of wrestling's character, but transgressing the spatial boundaries of the wrestling environment invites potential danger for participants, and even more so when interactional boundaries are subverted. Furthermore, these categories are not mutually exclusive, and subverting boundaries from one category often involves subversions in the others. When spatial boundaries are broken in the most literal waythat is, when performers wrestle outside of the ring - this also denotes a breaking of match rules (structural boundaries) and requires audience members to interact with performers in new ways by allowing the wrestlers to intrude into their space. 


\section{Structural Boundaries}

Under the auspices of kayfabe, professional wrestling is presented as a legitimate sport with a governing authority (the promotion that organizes an event) and a sanctioned officiate that presides over the events of a match (the referee). These guidelines structure the wrestling performance in that any match is set up pursuant to these governing rules and plays out in relation to them. Just as an attendee to a basketball game knows what basketball is "supposed" to look like based on its rules, so follows the format of a wrestling performance; the major difference between a wrestling match and an actual sporting event is that sports do not need to accommodate a pre-determined narrative in their performance, as the "story" of a game is only defined once the action is over. In small-scale wrestling, the majority of these rules are not explicitly stated but are learned by the audience through observation or through association with wrestling that they have seen prior, where announcers may be more detailed in their offerings of the rules. Wrestling matches have no set time limit, and only end once certain conditions are met. In the archetypal example, a match is over when on wrestler pins both of his or her opponent's shoulders to the ground for a set period of time (a "three-count," signified by the referee slapping the mat three times.) Matches may also end through forfeiture, disqualification due to the breaking of rules, or through meeting the special conditions of special match formats: in a cage match, for example, a cage is erected around the ring and the first wrestler to exit this cage is declared the victor. The conditions of a match are given by an announcer before the start: a match "scheduled for one-fall" means that the match ends on the first successful pin, whereas a "two-fall" or "three-fall" match requires more successive rounds. As in any sport, there is a set of illegal and prohibited techniques that are forbidden in legal play: wrestlers may not scratch or bite, the ropes surrounding the ring cannot be used to choke a wrestler, etc. Weapons, either 
improvised or otherwise, are strictly prohibited. In actuality, professional wrestling exhibits a large set of rules and regulations, generally adopted equivocally by promotions. This is not apparent at first glance, or at all, because these rules are effectively meaningless in wrestling's practice.

In the extent of my field experience, I am hard pressed to recall a match that was played "clean," or entirely by the book. While there is an application of rules and penalties in professional wrestling, this application is wholly inconsistent and is only enacted as the narrative of a match demands. In most cases, wrestlers won't even pretend to care about the rules, and violations start with the match's opening bell. The general wisdom is that heel wrestlers are defined by their willingness to break the rules, while face wrestlers struggle to maintain standards against their less valiant rivals. In actuality, both faces and heels break the rules prodigiously, it's just that heels tend to be the ones that break the rules first. Generally, the referee will be insistent in trying to govern the behavior of his charges, but won't actually disqualify a wrestler; his or her protests will wane as the match goes on and the rulebook will be thrown out entirely. Rules may be broken as egregiously as necessary. In my experience, I've seen a wrestler beaten into submission by three of his opponent's lackeys, a referee knocked out cold, and all manner of behavior that should have ended in blatant disqualification (if not arrest and criminal charges). But match rules are flexible in more subtle ways as well. The "threecount," for example, does not correspond to any fixed or discrete amount of time; it's length is as long or as short as it takes for the referee to count it out, always giving just enough time for a pinned wrestler to maintain suspense as to whether or not they will break out of a hold. (As the match endures, this plays out nearly to the point of frustration.) Similarly, wrestlers who leave the ring for any reason are given a ten-count to return, lest they be disqualified. This played out 
quite spectacularly in one instance when a wrestler buried his opponent under a pile of folding chairs and walked calmly back into the ring; once there, he sat patiently and smiling while the referee slowly counted from one to ten, his entombed and incapacitated opponent thus disqualified. Though most wrestling matches end with significant time spent outside of the ring, this is the only instance I saw where a wrestler was disqualified due to a ring-out penalty.

That wrestling's rules are entirely superficial is commonly understood, even celebrated, aspect of the medium for anyone even vaguely familiar with professional wrestling. The metal folding chair, applied as a blunt instrument against one's foes, is an iconic image, as are all the nefarious means by which unscrupulous wrestlers sneak their way up to the top of the roster. Even the notion that wrestling matches are "fixed," though vital to wrestling from a narrative standpoint, can be seen as another way in which the practice is synonymous with cheating and dirty tricks. Then from the perspective of boundary play's capacity to introduce the novel and unordinary into a performance, it seems at first that these transgressions are far from unique, challenging, or particularly transgressive at all. However, the structural boundaries of professional wrestling are important to mention for a couple of reasons. The first is that they demonstrate that, at a fundamental level, professional wrestling is about "breaking the rules." Boundary play is a part of its basic performance, and has been since the form was popularized in the early 20th century (Morton and O'Brien 1985). The egregious display of rule-breaking and unethical behavior in wrestling was, at one point in its development, quite radical, with confused and outraged audiences sometimes reacting in outrage to what they perceived to be blatant disregard for the rules of the game and their own sensibilities. This behavior also proved to be quite popular. Unlike other performance genres which treat boundary play as experimental, wrestling has since made this behavior normative, an expected and necessary part of the 
wrestling performance that is (at least implicitly) understood by audiences when they engage in spectatorship. But at the same time, wrestling's structural boundaries are important in that they still produce strong audience performances. Although audience members are quite familiar with wrestlers cheating during a match — they would have, of course, witnessed it in almost every match they had ever seen - they are always quick to react with outrage and indignation, as if they were seeing it play out for the very first time. (These reactions are pre-dominantly given to heels; face wrestlers breaking the rules are usually granted tacit permission for their actions.) This anger is not only reserved for the wrestlers, but also to the referee that blatantly demonstrates his or her inability to govern the match. This dynamic actually makes the referee an interesting character in the wrestling drama. While successful and well-performed referees can make a name for themselves in this role (there were a few "high-profile" referees in the community that I followed), "good" referees are rare: they are always incompetent, immoral, or both. And much like the heel wrestlers they supposedly defend with their inaction, successful referee performers must be able to gracefully manage nearly constant negative feedback from the crowd. Working in tandem, the "onstage" performances of the referee and the wrestlers that they (fail to) control inherently produce boundary play which the audience is meant to respond to, in order to maintain kayfabe.

\section{Spatial Boundaries}

The wrestling space is arranged analogously to legitimate sporting events, particularly boxing. The wrestling ring is set up in the center of the space and is surrounded by an aisle free of obstructions. Seating for the audience is set up around the ring on all four sides; depending on the location where the event is held, there may be bleacher seating or just a few rows of folding chairs. The audience is intended to say seated, or standing at their seats, throughout the matches, 
so as not to interfere with wrestlers making their way in and out of the ring. As one would expect, the wrestlers are "intended" to keep their activities in the ring at the risk of disqualification. In some matches, this rule is generally followed. Wrestlers may dart out into the clear aisle around the ring but will then return to the ring to continue the action. It's typically in the later matches of an event that the wrestlers begin to leave the ring. Here, the stakes are too high and the action too intense to be contained by the performance space; in actuality, the entire space becomes a potential playground for wrestlers to throw each other around. This includes the direct area occupied by the audience, who is sent running away as bodies are set crashing into the chairs that they were sitting in a few seconds before. Anticipating when it is best to flee from one's seat is a bit of an acquired skill, best learned from fans who are far more accustomed to mayhem. By the end of these matches the audience is scattered in small gatherings around the room, continuously moving to get a better view of the action.

As one would expect, there is a real possibility for physical harm for both performers and audience members when spatial boundaries are transgressed. The time it takes for a seating area to transform into an extension of the wrestling space can be very short, and can come when one least expects it. For those that are unfamiliar with how these matches proceed, the effect can be especially startling. Newcomers often have to be vocally reprimanded to get out of the way by audience veterans, lest they be put too close for the wrestlers to act safely. But in my experience, the wrestling audience typically does a good job of reading when the wrestlers are about to make the leap out of the ring, and are quick to react accordingly. In the cases where the audience perhaps didn't understand the risk of this engagement, on-hand attendants would step in to form a physical barrier between the wrestlers and the crowd. 
Despite the risks present, in my time at matches I never witnessed an audience member come to any undue physical harm as a result of a wrestler's actions. I believe this speaks to a shared commitment to safety between performers and audience that was able to develop in the relatively small wrestling community that I frequented. Audience members generally tended to respect the space that wrestlers needed to do the work of their performances, even when that space intruded on their own. (At the least, their sense of self-preservation was strong enough for them to maintain this avoidance.) And the wrestlers, even though they were engaged in pushing the comfortable boundaries of the performance, had a capability to interpret acceptable interactions with the audience. This is no small task; in every crowd, each individual will have a different degree to which they are willing to engage in boundary play. Some fans, like the ones mentioned at the opening of this chapter, are more than willing to go to the extreme in interaction, up to being the deliberate target of (performed, but nonetheless dangerous) physical aggression. But this cannot be assumed to be the norm for all attendees. Being able to read the crowd en masse and figuring out who is more agreeable to these interactions, and doing this whilst in the middle of a match, is a degree of sophistication in wrestling performances that goes mostly unrecognized in wrestling scholarship.

\section{Interactional Boundaries}

These are the rules that dictate the interactions between wrestlers and audience members. As mentioned previously, the crowd at a wrestling event are expected and encouraged to be rowdy and to express their approval and dissatisfaction with the wrestlers. Face wrestlers will be met with cheers and chants, while heel wrestlers will be met with outright insults. For their part, heels will return this treatment and have no qualms with picking out any random crowd member for (verbal) abuse. Beyond this, it is often explicitly stated that audience members should make 
no physical contact with the wrestlers. But this rule is broken in a "safe" way at the beginning of many matches, as face wrestlers will run around to collect high-fives from fans as they make their way to the ring. One heel wrestler had his own way of "greeting" the audience when he would come out: while wrestlers are supposed to make use of the aisles between chairs to reach the ring, he would instead walk through the rows, pushing people (still seated) out of the way in the process. For general audience members, however, physical contact is still kept to a minimum.

For certain fans, such as the ones from the introduction to this chapter, these interactions can be taken considerably further. Physical and verbal interactions between the wrestlers and crowd members can be elaborate, seemingly alarming, and have direct results on the match itself. At one event, I was seated behind a woman and her husband, both of whom were photographers. Throughout the night they left their seats to position themselves around the ring, taking pictures from various angles and viewpoints. They presumably had some connection with the promotion; I recognized them from earlier events at this location, and this promotion would always publish hundreds of high-quality photographs from their matches. This was the final match of the evening, a high-stakes bout between two bitter rivals, a longtime local hero and a hot-headed, arrogant newcomer. This match was billed with the qualifiers "no disqualifications, no submissions, pins count anywhere." With respect to match rules, this meant that "regular" penalties were suspended, the match could end through forfeiture (submission), and that pins were legal outside of the ring. But this could potentially be true for any match; the subtext here, the implied promise to the audience, was that things were going to get wildly out of hand. And they did, but at this early point things were still relatively controlled. The wrestlers had just gotten themselves out of the ring, and were making their way around its edges, smashing heads into the corner posts, using the ropes to strangle each other, and so on. They were now occupying 
the aisle facing our seating area, and the photographers used this opportunity to get a closer vantage point. At this point, the heel had taken the upper hand, his opponent trying to pick himself up off the ground, momentarily stunned. In this short reprieve, the heel looked up and noticed the woman snapping pictures of the scene. Acting out of wicked cleverness, he walked up to the woman taking pictures and snatched the camera out of her hands. With this new weapon in hand, he approached his opponent, now almost back on his feet, and slammed the camera into his back, smashing it into a hundred little pieces on the floor. The woman howled at this, a piercing scream that commanded the entire room, her husband uselessly trying to get her to calm down. In the shock of the moment I couldn't quite make out the half-articulated stream of expletives coming from her mouth, but it was clear that this woman wasn't having any of this. And now the tables were turned. Our hero, now back to his sense, grabbed the now-exposed film roll off the ground and used it as a makeshift garrote against his foe. The woman yelled again, this time a different sort of emotion: half-triumphant, half-enraged, out for blood. Like something from the coliseum.

This moment took place in about ten seconds or so, but colored the rest of the match. The boundary play on display here took a significant degree of commitment from both the photographer and the wrestler that accosted her, but it led to a wholly unique improvisation that, although it really involved no "wrestling" at all, became the centerpiece of the match. People approached this woman after the show was over, asking if she was alright. Though flustered, she was apparently not that taken back: she and her husband would be back at future matches, snapping pictures with a new camera this time. A question stands for instances like this; was this a natural decision, made by the wrestler in the heat of the moment, or was it planned out beforehand? Was this woman working as a "plant" for the promotion, a common criticism of 
wrestling moments that take place outside the ring? A companion that attended the match with me was adamant that this was the case - the camera in question was an old model, which a photographer wouldn't use for typical purposes. If this were the case, then the woman involved was an exceptional actress; long after the match was over she was still around, red-faced and talking rapidly, chewing out one of the promotion managers. I cannot say that I know the complete story about that night, but on retrospection am inclined to believe that it was premeditated to some degree. But I also now realize that even if she was acting as a plant, the moment that transpired still holds significance. "Planted" occurrences in wrestling would only serve to bolster the boundary play that already takes place at these performances. For the more casual spectator, a wrestler breaking a bystander's personal property exists alongside the other transgressions that take place in a more regular manner and involve more of the audience, such that there would be no possible way for all of these instances to be pre-planned. "Natural" moments of interaction collaborate with those that are possibly planned beforehand, and the resulting effect is the creation of a space where the outrageous and unthinkable is always possible. Furthermore, in a community such as the one that I was following, there is a possibility for anyone to become a "plant." Regular, devoted fans were often given opportunities to work themselves into the performer's position; when one promotion's announcer stepped down from his position, a long-time fan took his place, now becoming his own character in the wrestling drama. For any fan at these events, there exists the idea that they could be the next "plant," so long as they are willing to commit to the performance.

Boundary play is an endeavor that entails significant risks for all involved players. Beyond the dramatic, highly visible possibility of physical danger at wrestling matches, there is also a constant possibility of violating the boundaries of social permissibility. And to an extent, 
pushing what is socially permissible is the entire point of boundary play. Being insulted by a heel, or being forced from your seat as wrestlers come crashing into it, is intended to be uncomfortable, at least at first. But the continued transgression of boundaries becomes something enjoyable and particularly unique to the wrestling experience. It speaks to an intimacy in the relationship between performers and audience members within the performance; permitting these exchanges necessitates trust between participants and entails something special, which might not be attempted with a more "generic" audience.

Nevertheless, there are still situations where boundaries are pushed too far. There have been tense moments during my outings, where one party either committed too strongly to the performance, or intentions were misunderstood, etc. Wrestlers and angry spectators have been separated physically by event attendants, though this was the most serious form of disturbance that I personally experienced. I have also heard accounts of heel managers (characters that act as coaches for wrestlers; managers of heels typically exhibit the same bad behavior of their charges) being spit on or having things thrown at them, but this is certainly a rare occurrence. In wrestling, the fine line between pushing boundaries too far and pushing them just far enough is constantly being tread. For wrestlers, understanding how to employ boundary play in a performance, when to do it and towards whom to direct it is a learned skill; knowing an audience, and working with them, is essential to a successful performance.

Professional wrestling, especially in small-scale, local venues, provides a fruitful environment for boundary play to be attempted and experimented with. Audiences here are relatively small, so audience members who attend frequently and are active in performing their roles can easily lose their anonymity and become familiar faces. The serialized nature of professional wrestling promotes regular attendance for committed fans, so wrestlers can 
recognize those individuals who keep coming out time after time. Even though I was far from the most active fan in the crowd, over time I was being recognized by the performers — and, on occasion, singled out for (verbal) abuse by the heels, something which I accepted as a compliment. Compare this environment with a more traditional theatrical venue, where audiences are typically larger, more passive, and repeat attendees are rare. For audience members, repetitive attendance also allows one to grow more comfortable with the boundary play that is exhibited during matches. While I was at first taken aback with how forward wrestling performances were, but by my fourth or fifth outing I was growing familiar with the dynamics at play; while boundary play is never quite routine, it becomes something that can be anticipated and cultivated. The wrestling scene also gives audience members plenty of opportunities to learn appropriate audience behavior and to push their own performances. If one wishes to become the kind of fan that has their camera stolen or their throat grabbed, they need only put themselves out there as somebody who is willing to permit that. The regular activities produce familiarity for the audience on two fronts - personal familiarity with the performers, and familiarity with the expectations of the medium. Together these aspects of professional wrestling produce an environment where boundary play is not just novelty, but an integral part of the performance process.

I would be revealing my bias to say that small-scale events offer a more "genuine" wrestling experience, but it is in these spaces that boundary play can truly flourish. While televised wrestling may be more lucrative, the demands of the format ultimately stifle the creativity that boundary play can create. The wrestling viewer at home can certainly appreciate scenes of interactions and close calls, but can also write them off as being staged events; when these things can potentially happen, you gain a sense of appreciation for their immediacy, and 
the risks that performers make when they attempt them. Even for live audiences at large-scale televised events, the need for control by producers is too great to allow boundary play to become a guiding force in how performances play out. Moreover, wrestling on the small-scale gives fans a greater sense of ownership over the performances that they enjoy. A wrestler's success is ultimately defined by how fiercely they are loved or hated by the crowd; and if the crowd wants to love or hate something else, they can make their preferences known, and wrestler producers can tailor their product to meet this demand. Before and between matches, I heard time and time again how this was something being done expressly for the fans. While this is a common enough reassurance, in rings more truly when said before a crowd of 40 than for a crowd of 4,000.

In any performance, boundary play is a possible strategy for innovative and effective engagement between social actors. Experimentation on the edges of performance, where the worlds of fact and fiction meet, has been regarded as a compelling - if sometimes uncanny_force in modern theatre. But this play has found a comfortable home in the unlikely stage of the wrestling ring. At its best, professional wrestling produces a deep sense of ambiguity, a questioning of one's senses where outrageous and unbelievable is nonetheless taking place right before your eyes. And looking to one's peers around the ring, seeing the intensity with which they express their acceptance of this fiction, one can only choose to believe it. It is in this moment that wrestling becomes real. 


\section{CHAPTER IV: AN ANATOMY OF A FAILED PERFORMANCE}

I have often heard—-both first-hand from mentors and through myriad ethnographic accounts - that failure is an inescapable part of the field experience. In attempting to navigate the unpredictable worlds of other people's lives, we all inevitably reach a point where our assumptions and expectations fail to match the reality of a social situation. This is especially obvious when navigating the wholly unfamiliar settings that form the hallmark of anthropological analysis; indeed, in a fieldwork setting, this failure most often comes at the sake of the ethnographer, much to their embarrassment. However, failure is as invaluable as it is inescapable. The rules and responsibilities of basic social life, often unspoken and assumed to be universally understood, are brought into harsh relief when they are not met. For the guest, failure to meet a host's expectations often becomes an awkward lesson in proper etiquette; much like the child who literally knows no better, the anthropologist becomes wholly dependent on their host to understand why certain behavior is "right" and "wrong." For the observer who is (mercifully) a third-party to a scene of social failure, there is an opportunity to better grasp the dynamics at hand in a given situation: who screwed up, what did they do wrong, why? Successful ethnographic inquiry, in some sense, comes as the result of a sequence of carefully negotiated disasters, close calls, and awkward experiences.

My own run-in with failure in the field has been hard to leave behind and in some sense informs the entire character of my research. As an explanation, and in my defense, I was hardly to blame for this experience: failure was not a result of my own action or inaction. This, instead, is an account of what I consider to be a failed performance of professional wrestling. It should be noted that, generally speaking, professional wrestling is no stranger to mistakes. At its best, wrestling is a form of planned chaos, which demands the extremely precise execution of physical 
techniques between two (or more) wrestlers in an improvised performance. Small mistakes or blunders, termed "botches" within the wrestling community, are actually quite common; expertise comes from hiding these botches from the audience, or otherwise mitigating their impact on the greater performance. Even at their most egregious-I've seen a few matches where injury has required the temporary suspension of "normal" events-botches have never overshadowed the overall success of the performances that I've witnessed. This particular event, the only one that I've seen that I would characterize a "failure," was victim to a different sort of trouble. Failure wasn't really due to the mistakes of the wrestlers, nor did it necessarily come from within the audience. It instead arose as a grave miscommunication, a fundamental mismatching of expectations between performers, audience, and myself which finally coalesced into an unsettling display of mediocrity. The professional wrestling audience, I argue, has a performative character which is no less important than the brawl that takes place within the ring. When this performance is not adequately realized, the resulting dissonance effects all parties involved and effectively sours the whole affair.

This event took place around mid-August, nearly a year after I began my regular attendance and observation of wrestling matches in central Illinois. By this time, I had become familiar with the local wrestling scene, and was used to the weekly drive to the neighboring city to see matches. This match, however, was a special event being held about an hour from the regular venue in a town I'll call Lender, a place that I've known very well my entire life. I grew up in a town of 1,000 people with little more than a gas station, we had to travel just to get groceries. About twenty miles from my hometown, Lender has been and is a regular destination for my family. The promotion holding the event, Zero1 USA Supreme, had previously done a show in Lender that was an excellent example of a wrestling "success," drawing a large and very 
enthusiastic audience. I was also quite familiar with Zero1, as they had served as my introduction to local wrestling a year before and I frequented their matches since. While wrestling had become a regular part of my life, I cannot deny the significance I gave to this particular event; in a sense, it was an anniversary, a now-familiar activity in a long-familiar setting that would mark my experiences in the wrestling community thus far.

\section{The Main Event}

The matches of that evening were open to the public with free admittance at the local shopping mall, and were being hosted as a part of CIL-Con, a small fan convention devoted primarily to paranormal fiction and media but also to the wide variety of standard con faire: anime, video games, comic books, and other aspects of "nerd culture," including professional wrestling. I arrived about an hour before bell time to scope out the convention and to get a feel for how the wrestling was being received by attendees. The mall itself is set up like a giant hallway with stores lining the sides, and for the occasion was packed with vendor stands selling autographed books, commissioned illustrations, ancient video game consoles, and the like. In a room off to the side, two men were telling stories about hunting ghosts in the Alabama countryside. The wrestling ring was already set up by the time I arrived, claiming a vast, empty room which, up until very recently, had been a Sears for far longer than I had been born. a few of the night's featured wrestlers were there as well, helping to set up chairs and equipment or otherwise chatting amongst themselves and eyeing the convention, a drastically normal display compared to the fierce and bombastic personas on display in the ring. Thirty minutes before bell time, this all changed as wrestlers descended upon the convention, in costume and in character, to invite people to the matches about to happen. Unsuspecting con-goers and vendors were singled out and asked (or, rather, told) to attend. One wrestler, clad in animal skins, took over a 
local radio station's table, barking commands into a live microphone. In an instant, Zero1's presence at the convention took a dramatic turn and became the night's main attraction. I took this as a sign to join the growing crowd around the ring.

As bell time grew nearer, the excitement in the space became palpable. Promotion workers struggled to find more chairs and places to put them. (A good problem to have for a wrestling event, generally speaking.) Audience members had to be moved from the aisles that wrestlers would use to enter and leave the ring, and in the end there was a large group left standing near the entrance of the room. One thing that I noted as the matches began was that the crowd was largely unfamiliar to me. This was to be expected, given that this was a special (and free) event, but Zero1's shows were typically attended by a core group of frequent, regular fans. With the exception of a couple of faces, this core group was missing, perhaps because due to the distance from the normal venue. I didn't pay much mind to this at first; after all, the "foreign" audience at the last Lender show behaved just as I would expect from a typical wrestling crowd. But the differences between this show and the ones I was familiar with would become clear very shortly.

Before the first match, the announcer came to the ring to welcome the crowd and rouse up excitement for the upcoming matches. He also brought out a "special guest," one of the ghost hunters from before, who talked about how great CIL-Con had been so far and how appreciative he was of the con-attendee's general enthusiasm. He was also a huge wrestling fan, as luck would have it, and was eager to see what Lender had to offer; the perfect setup for a heel wrestler to come in and spoil all this optimism. Like clockwork, entrance music signaled the entrance of the evening's first competitor. The purpose of a heel (or villain) character in professional wrestling is to give the audience somebody to root against, to draw their ire and displeasure in a variety of 
ways: he may be annoying, offensive, bizarre and monstrous, or generally rude. Regular heels, like all professional wrestlers, have a distinct character that comes from their performance, a unique way of connecting (or, with heels, disconnecting) with the audience. This wrestler, however, was a new addition to Zero1's roster, and from all I could tell was a newcomer to professional wrestling as well. (That summer was the beginning of a new "season" for Zero1, which brought in several new wrestlers.) For new and unfamiliar wrestlers, it is important to quickly establish a connection with the audience and to make it very clear what sort of character is being performed. And while it was clear that this wrestler was a heel, it was also clear that his heel tactics weren't going over well with the crowd. That is not to say that the audience was displeased, as that would have been a desired response; the standard heel is met with boos, jeers and insults, and the best heels will draw people out of their seats, screaming and calling for punishment. This wrestler's actions, however, prompted little response from the crowd at all. His silent glares to nobody in particular and excruciatingly slow walk around the ring only elicited a few snorts and chuckles. When he finally entered the ring, he stated his "purpose" for being there that night, disparaging the fine name of Lender and its residents and threatening the ring's guest: standard moves in the heel's repertoire. His calls for a challenge were finally met by another wrestler, a Zero1 regular who usually performed as a heel himself (and a fairly good one at that). With two competitors at each other's throats and ready to go, a referee was called in so the match could begin in earnest. Like the first wrestler, the referee that came out was also a newcomer to Zerol's roster. It should be noted that, although they are usually unsung actors in the ring, referee performances are no less complex and nuanced than those of the wrestlers. Referees are a fundamental part of the wrestling performance, helping to shape the narrative of a match and drawing certain behaviors from the audience. They also aid the wrestlers, subtly 
guiding their improvised performances with one another. While a skilled referee is mostly ignored and blends into the greater action of the match, an amateur referee sticks out like a sore thumb.

The actual wrestling in this first match does not require much comment. While it was obvious that the heel was still learning the ropes, he generally did a serviceable job and seemed to have a good rapport with his opponent. The referee's performance, as mentioned, was harder to ignore; his calls to the wrestlers were too loud, his demeanor too dour, and he had a habit of always standing in between the crowd and the action. The most noteworthy performance wasn't taking place within the ring, but rather around it. Throughout the match, the audience at large maintained an overbearing silence, breaking only to give a few claps at points where one wrestler overturned the other or escaped a pin. To provide a contrast, the matches that I was familiar with were noisy above anything else. Cheering, chanting, booing and screaming seemed to be a natural feature of the wrestling space. A referee's calls would be all but drowned out by the sound, as would the wrestlers' insults to one another and, more importantly, the whispered messages that would plan their next moves. To watch a wrestling match stripped of this ambience was a fairly novel experience, though not entirely unprecedented. The first matches of a night, especially for special events, were sometimes set aside for freshman wrestlers getting a feel for working in front of a crowd. These matches could be more quiet than usual as audience members would still have their attention devoted elsewhere: finding their seats, settling in, getting concessions, or otherwise not yet "into it." On a regular night, it might take a match or two to get the crowd really worked up. The response to this match, however, proved to be an omen. The match ended, a humbling defeat for our boastful heel, and the victor was received 
with applause that was little more than polite. So it would be for the second match, and the third, and beyond.

As the night went on, the crowd's restraint took its effect. When it became clearer that the silence wasn't going to break easily, things started to become awkward. Without the crowd as a distraction, the minute imperfections of the performance became more easily scrutinized. The small mistakes, pulled punches, and whispers that were usually washed away were laid bare, exposed for everyone to see. With each match, it became more and more obvious that the weight of this silence was taking its toll on the wrestlers. Admonishments to "make some noise," a desperate act of resuscitation, became more frequent and sometimes angry. Wrestlers who were fan favorites looked to the crowd for recognition, and were met with mute stares. The few fans attempting to make their voices heard (myself included, admittedly) were now the exception and not the rule, and their "outbursts" would earn glances, not mimicry. At times, I thought, the spectator's gaze took on a tone of judgment. While the regular crowd at a Zero1 show knew who and what to expect, and how to react to it, this crowd demonstrated that it still needed to be convinced.

About halfway through the event, one wrestler attempted to take matters into his own hands. Bear St. Pierre, a long-time veteran of Zero1 wrestling (and one of the first local wrestlers I saw perform), is one of the more colorful characters in the roster. Standing somewhere between grizzled mountain man and ancient Norse deity, Bear had recently incorporated a new gimmick into his entrance routine: a crude war hammer crafted out of wood and stone (or, rather, Styrofoam or papier-mâché) which apparently held tremendous power. Before his matches he would brandish it at his opponents and slam it onto the ring, causing the referee and the other wrestler to pantomime being thrown from their feet in shock. When the referee would try to clear 
it from the ring to start a match, he would pretend to be unable to lift it from the mat. While the theatrics of this display were obvious, it was the dedication with which the other actors committed to it which pleased the audience and gave a spectacular effect to the performance. Tonight, however, the other actors weren't so committed. Referee and opponent alike stood and stared at Bear as he thrashed the mat with his hammer, bemused expressions mirroring the one coming from the crowd. What was an aggrandized, melodramatic show of strength was reduced to a man vainly beating the ground with a toy. Not to be discouraged, Bear then tried to win the crowd over with humor. Instead of getting ready to wrestle, he reclined on the ropes and tried out a stand-up routine, taking potshots at the other wrestler and at the crowd. While this was typical of other wrestlers, Bear was typically the type who let his actions do the talking, and this change of form was also not very well received. Nobody was really laughing, and soon some members of the audience were getting restless, urging both wrestlers to get on with the show. While the antics didn't continue for much longer, the match itself didn't recover from its stilted beginning. Bear's finishing move, a body slam from the top of the ropes, was botched and had to be set up and attempted twice. While he left as the winner, Bear left the ring red-faced and fuming, muttering expletives under his breath; hardly the demeanor one would expect from a victorious, and typically good-natured, wrestler.

After two hours that seemed to draw on for far too long, it was finally time for the main event, a bullrope match for the Zero1 Heavyweight Championship. In a bullrope match, the competitors are tied together and the match ends when one wrestler taps the four turnbuckles in the corner of the ring in succession. Beyond this, special matches are typically advertised as being no-submission (a wrestler can't "tap out" of the match due to pain or an inability to continue) and no-disqualification (moves typically moved as illegal are considered fair game), 
thus promising to provide a maximum level of carnage for the viewer. Anticipation for the match had been built up over the preceding weeks, and both wrestlers were fan favorites. On one end was Frank Wyatt, the reigning Heavyweight Champion who had defended his title—often through nefarious means - for about a year. Wyatt is a giant of a man, built like a sumo wrestler and notorious for his power and brutality, often leaving his opponent in crumpled heaps on the ground. Challenging Frank Wyatt was Shank Barzini, a past favorite who had recently made a return to wrestling in Zero1 events. Barzini's character is an edgy, in-your-face madman, known for his ability to inflict and receive serious damage in the ring. I had seen Wyatt and Barzini clash a few weeks before in a match that ended with Barzini buried under a pile of folding chairs, nose smashed and lying in a small pool of his own blood. This didn't seem to deter Shank, who was back and ready to settle things in his typical fashion. While the night up until now had been dismally received, this match was a perfect storm I hoped would finally bring something out of the crowd.

Main event matches tend to share similar features among them. On a surface level, the purported stakes are higher (titles are on the line) and they occasionally feature rule variants, like the bullrope or cage match. But beyond differences in rules — which are, essentially, a fiction — these matches tend to have common performative features as well. The main event is always the longest match of the night, sometimes going on for twice as long as a typical match (if not longer) with the longest going on for 30 to 45 minutes. While this could be tedious, in practice the wrestlers are usually skilled enough to keep the action varied and dramatic enough to keep the audience invested for the entire duration. Wrestling in these matches tends to be at its most grueling, and it's not uncommon for wrestlers to leave the ring bruised and bloodied. Also recall that in wrestling, the action is rarely confined to the ring; this is especially true for high profile 
matches like this, where audiences are expecting a little more mayhem than usual. While other matches may have wrestlers leave the ring temporarily, in the main event this is where a majority of the match takes place. It is outside of the ring that professional wrestling truly shines, as wrestlers make full and creative use of all the space provided them. Chairs, trash cans, carts, and any other objects left around become improvised weapons. Any assumed physical distance between wrestlers and audience becomes superficial, as the action is literally brought to the crowd's feet; while the crowd spends the majority of the night sat around the ring, at the night's end people watch from small groups scattered around the space, having fled from wrestlers as they were thrown into the seats. Here we see professional wrestling at its most engaging and exciting, a unique aspect of the performance which necessarily incorporates the audience.

And so it was in this match. While the first 10 minutes had Frank Wyatt and Shank Barzini squaring off in the ring, they quickly found opportunity to take the fight over the ropes and begin the match in earnest. Finally, the crowd was beginning to show some excitement. Initial shock at watching the wrestlers perform seemingly (and actually) dangerous moves onto the hard concrete floor quickly turned into enthusiasm, and the air was filling with shouts and cheers. But now a new problem was forming. This transition to wrestling on the floor is potentially dangerous for both wrestlers and fans, and requires that both parties be very aware of everything that is going on around them. As I have mentioned previously, proper wrestling spectatorship involves learning some vital skills of self-preservation. Realizing that a wrestler is about to come flying at you takes a little getting used to, and the performers need to trust that the audience knows when they need to get out of the way. When I first started going to shows, I had to watch the other fans to know when it was time to scramble out of my seat, but as I got more accustomed to the wrestlers I began to get a feel for when performers were setting up to leave the 
ring. This audience, generally, was not aware of how dangerous this situation could get, and tried to get very close to the wrestlers as they tumbled onto the floor. The man filming the show began to shout at the crowd, telling them to get out of the way and fast. The promotion crew ran over to try and squeeze themselves between the wrestlers and anyone who got too close. After enough goading, people finally realized that keeping some distance was a wise choice, but still packed themselves tightly around the wrestling. Throughout this ordeal, everyone came out fortunately unscathed - with the exception of the wrestlers, though there were no unpleasant surprises for them. To their credit, the wrestlers never slowed down their brawl while maneuvering themselves away from potentially risky situations. With the safety of all parties more concretely established, both could begin the long, brutal slog towards victory. This match was edging towards being one of the longer ones, and as it neared the 30-minute mark the excitement began to dwindle again. While I had been perturbed at the night's events for a long time before, I now began to think that something needed to change. Despite the weak showing of the crowd, all of the wrestler's that night never complained and gave exceptional performances no matter the circumstances. And as Frank Wyatt and Shank Barzini beat each other to a pulp to rapidly dwindling applause, I mustered up the courage (ad the delusion) into thinking that one voice could tip the crowd into a fervor. I wanted to make sure that they, and everyone else who was listening knew that they were appreciated, and so amidst the silence I tried to shout a chant I had heard many times before:

\section{"ZE RO ONE! ZE RO ONE! ZE RO ONE! ZE RO-"}

And then the gaze was directed towards me. Rather than taking up my poorly planned call to action, I was now the center of attention as far as I could see. I don't know if it's difficult for other people to be the only person shouting in a room full of staring strangers, but 
immediately all of my courage withered up inside me. I was now the weirdo, the rube who bought into the professional wrestling farce. Rather than be the center of attention for any longer, I shut myself up and resigned to letting the silent majority win the night. But there was one more disturbance left: one of the regular fans, who I had seen at every Zero1 show I had been to, elected to pick up where I left off in a final act of frustration:

"ZE RO ONE! ZE RO ONE! Oh, COME ON people!"

After attending wrestling, I usually leave awash in the dramatic, emotional sway of the night's events. It is one thing to "observe" wrestling as an object—as moral theater, as melodramatic performance genre, as fiction, etc. - but it is another thing entirely to be in it, to see the spectacle unfold, to become the subject of an affective display. Even though I always came acutely aware that I would be watching a "staged" production specifically designed to bring out desired emotional states in its audience, in certain cases there was no amount of theoretical preparation sufficient to make me remember this as it was happening. I've walked away with feelings of victory and satisfaction as well as fury and disgust at a match's outcome. Suffice to say, it can take some time and separation to "cool down" after a match and attempt to break down the dynamics that took place within it. Leaving this show, however, I was nothing but analytical.

Driving home with my brother (another converted wresting fan, he often comes along with me), we immediately began to try and make sense of the affair we had just witnessed. Together we picked out the moments that stuck the most in our minds, and attempted to pinpoint the exact moment things became irrevocably derailed. We first targeted the weak spots in the wrestling performance: the mediocre novice in the first match, Bear's ill-fated attempt to reach the audience with comedy, the awkward refereeing. But on any other night, mistakes like these 
would be lost to the larger scale of the entire wrestling spectacle. While these problems were significant now, I was and am reluctant to "blame" them for the audience's tepid reception. Neither did there seem to be any ill will from the audience itself; in an attempt to downplay my perhaps overdramatic account, the failure in this performance was subtle and mostly unmentioned. There was never much disgruntled or frustrated behavior coming from of the crowd (indeed, that would have probably been more desirable than what did happen), and aside from a few offhand reactions from some of the wrestlers, there was little comment from the other side of things. For the average spectator, who had not spent hours of their time frequenting shows in the area, it is likely that the event seemed typical of local wrestling with nothing standing out as particularly troubling. Unfortunately burdened with comparisons to the regular turn of events in these matches, I am left to explain why this particular performance came out as a failure.

\section{The Post-Mortem: When Heat Fails to Catch}

So, what had happened? To start, I propose that this event was the result of "a disjuncture between audience expectations, [the performer's] understanding of these expectations, and the performance itself" (Flueckiger 2013[1988]: 127). Analyzing another example of a failed performance, Joyce Flueckiger presents this case as the outcome of a sequence of events which lead the audience to expect one form of a performance that was different from what was delivered. In this particular example, a musical and dance-based recitation of an oral epic in central India, a "preceding series of frames" (129) — the set-up of sound equipment, criers announcing the show around town with accompanying Bollywood music, a relatively wealthy patron (the author herself), among other things — seemed to indicate to the audience that this would be a $n \bar{a} c \bar{a}$ performance of the epic, an extravagant "dance-drama" (125) style with 
costume changes, multiple actors, and complete musical accompaniment. When they were instead met with a simpler, toned-down, more rural-style git performance of the epic (125), the audience was disappointed and largely abandoned the performer. Failure, in this case, was not based on the performer's inability to give a good $n \bar{a} c \bar{a}$ performance, but rather in the fact that he had not intended to give a $n \bar{a} c \bar{a}$ performance at all; indeed, Flueckiger proposes that the performance could have been successful had it been more accurately advertised and had the performer sought a more "rural" audience that was more familiar with the git performance (129).

Returning to the wrestling example, we may consider the ways in which audience expectations were not met with this performance. While this show was billed as a main event for the convention it took place in, the wrestling itself wasn't "special" in that it was typical of the regular show a fan would attend: experienced and beginner wrestlers were showcased, there was no attempt to book big names for an appearance, and there were no dramatic upsets in the narratives produced through preceding matches (likely because general audiences wouldn't know these narratives beforehand). It is also possible that the general audience had expectations influenced by professional wrestling's most popular and well-known promotions, such as the WWE (World Wrestling Entertainment). While local promotions like Zero1 typically follow the format and style laid out by the WWE, the two are vastly incomparable in several ways. A WWE match, most obviously, is backed by a multi-billion dollar enterprise that draws on a highly selective roster of skilled performers who wrestle as a career. A local promotion, on the other hand, consists of part-time wrestlers (who are nonetheless also very skilled, given the circumstances) and operates on a small budget. Beyond differences in resources, the wrestling shows I attend also differ stylistically from the WWE in that they are more "action-oriented" in terms of their narratives. While a match between two wrestlers in the WWE will be preceded by 
a long period of escalated tension created through scripted "promos"—-scenes between characters, either conducted live before the match or previously recorded. While local wrestling matches also have these conflicts and narratives, and in some cases even have promos as well, they tend to be underemphasized compared to the wrestling itself. Generally speaking, the audience member comparing a small regional show to the WWE is naturally making a judgment as to the quality of the performance. But this is an obvious statement; what is more salient to our failed performance is the expectations that the performers make for their audience.

Amongst the professional wrestling community, audience behavior within the context of a performance is called "heat." There is some ambiguity as to the usage of this term. In some cases, heat generally refers to all audience behavior, while in others heat defines negative behavior (boos, insults, etc.) and is contrasted with "pop," referring to positive behaviors and expressions of encouragement. For the purposes of this analysis, I prefer to employ heat as a general term for audience behaviors for two main reasons. First, both positive and negative reactions from a wrestling audience are planned for and cultivated by the wrestlers and the promotion; they are intended responses to some action, deliberate or otherwise, made during a match. Second, both positive and negative reactions are desirable during a match, and no effort is made to limit an audience's negative response to a wrestler as long as this behavior is limited to verbal aggression. Indeed, professional wrestling is perhaps unique in that a wrestler can enter the ring, receive a great deal of hatred from an audience, and go home that night knowing that their performance was a job well done. It is this acceptance, elicitation, and encouragement of positive and negative reactions that distinguish performer-audience relationships in professional wrestling from other performance and athletic genres. 
For standing analyses of American professional wrestling (Mazer 1995; De Garis 2005), heat is central to an individual wrestler's performance and to the practice of professional wrestling as a whole. In other words, the general "purpose" of every event, match, promo, or action in wrestling is to draw enthusiasm (or agitation) from the crowd and to create an experience that encourages audience members to return. On a surface level, we might say that this is indicative of any performance; after all, a performance which fails to please its audience leads to an empty theatre or stadium, and little economic motive to continue production. But for the individual wrestler, and especially for those who are just starting their careers, heat is an allimportant and complex driving force in their performances. In addition to being competent athletes, wrestlers must create unique personalities for themselves that resonate with the audience. By forming a relationship — whether it be sympathetic or divisive — with the crowd, a wrestler secures recognition for themself that will hopefully endure beyond an individual match. Audiences will naturally be interested in seeing the development of a unique and "successful" character, and as a wrestler's reputation grows so does the stakes of their performances, and they might be involved in matches for championship titles or engage in personal feuds or alliances with other wrestlers that create ongoing narratives. Ideally, a wrestler wants an audience that knows their name, comes out and roots for them, and wears their merchandise. But it is important to remember that heel wrestlers are also building these relationships, albeit under different circumstances. A heel wrestler that is particularly despised will draw an audience that wants to see them humiliated in defeat, thus gaining a fan following in their own way. Whether they are loved or hated, wrestlers are successful when their performances are remembered. And for the wrestler in the ring, heat is a tangible signifier of how they are being received by the audience, and performances are constructed so as to create reactions that grow in intensity 
throughout a match. While it is important to remember that a wrestling match is not so much a competition as it is a collaborative endeavor between wrestlers (De Garis 2005), we must also recognize the "metagame" that heat defines for actors in the ring. Just as wrestlers work together to produce the narrative of a match, they are also struggling to create heat for themselves. So even if a wrestler knows that they will be losing a match, they still may walk out of the ring as the star of the show, so to speak. For wrestlers who are just starting out, earning a reputation is an uphill battle. New wrestlers are often employed as "jobbers," whose purpose in the wrestling narrative is to lose to established wrestlers as they claw their way to the top. They are essentially side characters in the larger wrestling drama, but may take center stage if they are well received by the audience. While they may be constrained by their role in a match or their character's traits, wrestlers may earn heat for themselves in several ways. Particularly skillful athletic displays are an established and "safe" way to earn recognition, but wrestlers may also earn heat solely based on their personalities. A charismatic wrestler who establishes a unique character (through their costume, signature moves and techniques, personality, etc.) will be able to quickly build fame or notoriety. However, a newcomer who too quickly establishes a character that is overly unique or outlandish runs the risk of being labeled a gimmick and dismissed by fans. But then again, a particularly lame or annoying gimmick may come full circle and be successful: when Zero1 introduced a heel who wore a baseball uniform and ran home runs around his opponents he was resoundingly mocked, but his gimmick stayed as the crowd warmly received his defeats. In short, a wrestler has many choices that could establish their character as a mainstay in a promotion's roster, but none of them guarantee success. It is only through heat - the immediate and direct reception of their choices - that they can evaluate their own performances and plan for future matches. 
In the case of the Lender show, the audience quite simply failed to produce heat for the wrestlers. While it'd nearly impossible to delineate why this audience was mostly silent throughout the evening, we may turn to some possible factors. The relatively small size of the event in relation to what people would expect from televised matches and the presence of observers outside of the audience (that is, the rest of the convention) may have persuaded the crowd to keep quiet. Audience members who weren't familiar with local wrestling may not have realized that constant noise was considered appropriate in this context, or that booing at wrestlers was acceptable. Whatever the reasons, it was clear to me that this lack of response from the crowd had significant consequences for the entire performance. A wrestling match sans heat is an unfamiliar thing, and for performers who expect a boisterous crowd it is an undesirable thing as well. Without the audience's input, it would be difficult to for a wrestler to gauge how they were being received and if the intentions of their actions were successful. Furthermore, the silence also expressed a degree of unfamiliarity with wrestling and what could occur in the context of a performance. In a typical match and with a typical crowd, wrestlers (especially heels) often take surprising liberties with their interactions with the crowd. A heel usually has no qualms with picking out a specific audience member to make fun of, and especially well-known or active fans may be singled out for more intimidating gestures. One particular wrestler, also a heel, would often walk through the seats rather than around them, literally forcing audience members out of the way as he entered the ring. However, these actions are done with an audience that understands, or at least seems to understand, the context established by the wrestler's character and the performances that frame the match. With this crowd, none of these sorts of activities were attempted, perhaps out of suspicion or concern that they would not be received well. Ultimately, in a performance that is marked by a significant degree of closeness between 
actors in and out of the ring, silence served to create a distance that, in the end, couldn't be bridged by the performers. 


\section{CONCLUSION: TAKING WRESTLING SERIOUSLY}

My interest in professional wrestling, both as a subject of inquiry and as personal entertainment, is largely based on three attributes that I have uncovered over time, mostly linearly in the course of this research. The first was its surface spectacle. On the outset, I realized wrestling's capacity for mythic pageantry, its ability to transform nations and creeds into men and pit them against each other in an eternal struggle of good and evil. It evoked the rituals and ceremonies of other societies that I had studied about, here played for a culture that is often assumed to have "moved past" the need for such things. In wrestling I saw the joust, or the blood sport of gladiatorial combat; here rendered less deadly but no less bombastic. And as a narrative of conflict that unmistakably spoke to the ideals and beliefs of a society, I was initially intrigued by what wrestling had to say about our public culture in the United States.

The second of these attributes was wrestling's performative qualities. Taken on the level of individual matches, wrestling loses some of its aggrandized moral qualities; in many cases, a match is just two people fighting each other. But in seeing wrestling for myself, I recognized that the performance of wrestling is an incredibly complex and difficult process. Even the most basic wrestling match was full of techniques that, if performed incorrectly, could result in serious harm, and this harm could fall on one's self, one's performing partner, or even an audience member. Beyond this, wrestlers undertook their performances while creating characters for themselves, interacting and reacting to the audience in ways that required exceptional craft and nuance. That these skills could be honed and perfected in settings as "low-key" as the ones I frequented was astounding, especially considering that the people mastering these performances were mostly "amateurs" that stood to gain little economic or financial benefit from becoming wrestlers. I was equally taken by the audience, who invested a great deal in their own 
performances at ringside. These folks made the effort to believe in wrestling, especially at its most unbelievable, and it was through their efforts that these performances truly came to life. It was the authenticity of wrestling's audiences, and the dedication that they brought to their own performances, which largely inspired the course of this research.

The third is wrestling's tendency to captivate the emotions of its audience. Not just in the way that emotions are stoked and appeased through a match's events, but also in the way that wrestling becomes something more than "mere entertainment" in the lives of those that follow it. The wrestling fans that I often encountered were particularly devoted in their interest, and even "casual" fans had an incredible depth of knowledge of the medium that put me to shame. In the course of writing this, I have often wondered if I was just stating the obvious for the average wrestling fan, and their imagined scrutiny was just as nerve-inducing as what I would encounter in academia, if not more so. For many of these fans, this passion is the result of decades of spectatorship and cultivation, and interest that started in childhood and remained ever since. Wrestling, for these individuals, is something that has grown with them and that they have grown around. When wrestlers retire or promotions close, it can be an event worth shedding tears over, the end of an era and the passing of heroes from yesteryear. When seen from the outside, at its surface, I can imagine how such love for professional wrestling may seem ridiculous.

But I believe that it all makes sense. In the course of this thesis, I have attempted to demonstrate how professional wrestling utilizes boundary play as a performative strategy that transforms a stage performance into a community practice. The social dynamics of boundary play are not unique to professional wrestling; indeed, in defining its usage in performance, I hope that it inspires further consideration into how it operates in other performative modes and genres. But with regards to artistic performances in Western tradition, professional wrestling is perhaps 
unique in the degree to which boundary play has become a part of its normative practice. Through boundary play, professional wrestling has become a complex and transgressive form of performance art, and this complexity is all too easily ignored when wrestling is only considered at its surface, bereft of the individuals who work together to create a shared experience. Without these collaborators and their performances, wrestling fails to realize its potential; sure, the talent may be great, or the drama might be funny or interesting, but it plays without the magic that elevates the performance to something "real." By seeing professional wrestling for myself, and attempting to confront it as fans do, it has been my hope to understand this "magic," and how it has been so powerful in these performance spaces.

In "The World of Wrestling," Roland Barthes (1972[1957]) deems wrestlers in the ring as "gods" for their ability to reveal the face of justice in society. But gods are nothing without their adherents. Their divinity lives and dies by the wills of those who anoint the sacred spaces, recite the words and present the images, and who name the justice that the gods live by. So it is with professional wrestling, which thrives or fails according to its ability to meet its audience. In boundary play, I believe we can consider wrestling in terms of its possibilities as an art form and the messages that it can convey. In as much that wrestling has stayed the same- the matches that I attended were much the same that Barthes described almost 70 years ago-it is also a performance form that is constantly transforming and innovating. Since I began this research, even the relatively small community that I have followed has changed in critical ways; a host of new promotions and talent have risen to prominence while others have waned away. As these groups hope to win the approval of their audience, they bring new possibilities to the format. Boundary play allows the audience to own these possibilities and to shape the medium into something that is unique to them and their experiences. As long as wrestling listens to its 
audience, and meets them past the boundaries of their performances, it retains its capacity to act as the people's theatre. 


\section{REFERENCES}

Allison, Anne.

2000 Permitted and Prohibited Desires: Mothers, Comics, and Censorship in Japan. Berkeley: University of California Press.

Bakhtin, Mikhail.

1984[1965] Rabelais and His World. Bloomington: Indiana University Press.

Ball, Michael R.

1990 Professional Wrestling as Ritual Drama in American Popular Culture. Mellen Studies in Sociology. Lewiston, NY: Edwin Mellen Press.

Barthes, Roland.

1972[1957] The World of Wrestling. In Mythologies. Roland Barthes, ed. Pp. 15-25. New York: Hill and Wang.

Bauman, Richard.

1977 Verbal Art as Performance. Long Grove: Waveland Press.

1986 Story, Performance, and Event: Contextual Studies of Oral Narrative. Cambridge:

Cambridge University Press.

Bauman, Richard and Charles L. Briggs.

1990 Poetics and Performance as Critical Perspectives on Language and Social Life. Annual Review of Anthropology 19: 59-88

Beard, David E. and John Heppen.

2012 The Dynamics of Identity in the Communities of Local Professional Wrestling. In Sports Fans, Identity, and Socialization: Exploring the Fandemonium. Adam Earnheardt, Paul Haridakis, and Barbara Hugenberg, eds. Pp. 25-36. Lanham, Maryland: Lexington Books.

Bourdieu, Pierre.

1984 Distinction: A Social Critique of the Judgement of Taste. Cambridge: Harvard University Press.

Brottman, Mikita.

2005 Offensive Films. Nashville: Vanderbilt University Press.

Campbell, John W.

1996 Professional Wrestling: Why the Bad Guy Wins. Journal of American Culture 19(2): $127-$ 132.

Craven, Gerald and Richard Moseley.

1972 Actors on the Canvas Stage: The Dramatic Conventions of Professional Wrestling. Journal of Popular Culture 6(2): 326-336. 
De Garis, Laurence.

2005 The "Logic" of Professional Wrestling. In Steel Chair to the Head: The Pleasure and Pain of Professional Wrestling. Nicholas Sammond, ed. Pp. 193-212. Durham and London: Duke University Press.

Dyck, Noel and Eduardo P. Archetti.

2003 Embodied Identities: Reshaping Social Life through Sport and Dance. In Sport, Dance, and Embodied Identities. Noel Dyck and Eduardo P. Archetti, eds. Pp. 1-19. Oxford: Berg.

Farnell, Brenda.

2001[1995] Introduction. In Human Action Signs in Cultural Context: The Visible and the Invisible in Movement and Dance. Brenda Farnell, ed. Pp. 1-28. Lanham, Maryland: Scarecrow Press.

Farquhar, Judith and Margaret Lock. 2007 Introduction. In Beyond the Body Proper: Reading the Anthropology of Material Life. Margaret Lock and Judith Farquhar, eds. Pp. 1-16. Durham and London: Duke University Press.

Flueckiger, Joyce Burkhalter.

2013[1988] "He Should Have Worn a Sari": A "Failed" Performance of a Central Indian Oral Epic. In The Anthropology of Performance: A Reader. Frank J. Korom, ed. Pp. 124-132. Hoboken: Wiley-Blackwell.

George, David. 1989 On Ambiguity: Towards a Post-Modern Performance Theory. Theatre Research International 14(1): 71-85.

Geertz, Clifford. 2005[1973] Deep Play: Notes on the Balinese Cockfight. Daedalus 134(4): 56-86.

Ginsburg, Faye D., Lila Abu-Lughod and Brian Larkin. 2002 Introduction. In Media Worlds: Anthropology on New Terrain. Faye D. Ginsburg, Lila Abu-Lughod, and Brian Larkin, eds. Pp. 1-36. Oakland: University of California Press.

Goffman, Erving.

1961 Encounters: Two Studies in the Sociology of Interaction. Indianapolis: Bobbs-Merrill.

Henricks, Thomas.

1974 Professional Wrestling as Moral Order. Sociological Inquiry 44(3): 177-188.

Hill, Annette.

2015 Spectacle of Excess: The Passion Work of Professional Wrestlers, Fans, and Anti-Fans. European Journal of Cultural Studies 18(2): 174-189.

Jenkins, Henry III. 2005[1997] "Never Trust a Snake": WWF Wrestling as Masculine Melodrama. In Steel Chair to the Head: The Pleasure and Pain of Professional Wrestling. Nicholas Sammond, ed. Pp. 33-66. Durham and London: Duke University Press. 
Korom, Frank J.

2013 Introduction. In The Anthropology of Performance: A Reader. Frank J. Korom, ed. Pp. 1-7. Hoboken: Wiley-Blackwell.

La Pastina, Antonio C.

2005 Audience Ethnography: A Media Engagement Approach. In Media Anthropology. Eric W. Rothenbuhler and Mihai Coman, eds. Pp. 139-148. Thousand Oaks: SAGE Publications.

Levi, Heather.

2008 The World of Lucha Libre: Secrets, Revelations, and Mexican National Identity. Durham and London: Duke University Press.

Lord, Albert B.

2000[1960] The Singer of Tales. 2nd edition. Stephen Mitchell and Gregory Nagy, eds.

Cambridge: Harvard University Press.

Maguire, Brendan.

2013 American Professional Wrestling: Evolution, Content, and Popular Appeal. Sociological Spectrum 25: 155-176.

Malaby, Thomas M.

2009 Anthropology and Play: The Contours of Playful Experience. New Literary History 40(1): 205-218.

Mauss, Marcel.

1973[1935] Techniques of the Body. Economy and Society 2(1): 70-88.

Mazer, Sharon.

1998 Professional Wrestling: Sport and Spectacle. Jackson: University Press of Mississippi.

Mazzarella, William.

2013 Censorium: Cinema and the Open Edge of Mass Publicity. Durham and London: Duke University Press.

Migliore, Sam. 1993 Professional Wrestling: Moral Commentary Through Ritual Metaphor. Journal of Ritual Studies 7(1): 65-84.

Mondak, Jeffery J.

1989 The Politics of Professional Wrestling. Journal of Popular Culture 23(2): 139-150.

Morton, Gerald W. and George O'Brien.

1985 Wrestling to Rasslin': Ancient Sport to American Spectacle. Bowling Green: Bowling Green State University Popular Press.

Murphy, Patrick D.

1999 Doing Audience Ethnography: A Narrative Account of Establishing Ethnographic Identity and Locating Interpretive Communities in Fieldwork. Qualitative Inquiry 5(4): 479-504. 
Nippert-Eng, Christena.

2005 Boundary Play. Space and Culture 8(3): 302-324.

Pace, Richard and Brian P. Hinote.

2013 Amazon Town TV: An Audience Ethnography in Gurupá, Brazil. Austin: University of

Texas Press.

Remshardt, Ralf.

2004 Staging the Savage God: The Grotesque in Performance. Carbondale: Southern Illinois University Press.

Schechner, Richard.

2002 Performance Studies: An Introduction. New York: Routledge.

Schieffelin, Edward L.

1985 Performance and the Cultural Construction of Reality. American Ethnologist 12(4): 707724.

1997 Problematizing Performance. In Ritual, Performance, Media. Felicia Hughes-Freeland, ed. Pp. 194-207. London: Routledge.

Schulze, Daniel.

2013 Blood, Guts, and Suffering: The Body as Communicative Agent in Professional Wrestling and Performance Art. Journal of Contemporary Drama in English 1(1): 113-125.

Serrato, Phillip.

2005 Not Quite Heroes: Race, Masculinity, and Latino Professional Wrestlers. In Steel Chair to the Head: The Pleasure and Pain of Professional Wrestling. Nicholas Sammond, ed. Pp. 33-66. Durham and London: Duke University Press.

Smith, R. Tyson.

2008 Pain in the Act: The Meanings of Pain Among Professional Wrestlers. Qualitative Sociology 31(2): 129-148.

Soulliere, Danielle M.

2006 Wrestling with Masculinity: Messages about Manhood in the WWE. Sex Roles 55(1): 111.

Stallybrass, Peter and Allon White.

1986 The Politics and Poetics of Transgression. Ithaca: Cornell University Press.

Taylor, Joy T.

2014 "You Can't See Me," or Can You?: Unpacking John Cena's Performance of Whiteness in World Wrestling Entertainment. Journal of Popular Culture 47(2): 307-326.

Turner, Terence S.

1993[1980] The Social Skin. In Reading the Social Body. Catherine B. Burroughs and Jeffrey Ehrenreich, eds. Pp. 15-39. Iowa City: University of Iowa Press. 
Turner, Victor.

1964 Betwixt and Between: The Liminal Period in Rites de Passage. The Proceedings of the American Ethnological Society, Symposium on New Approaches to the Study of Religion. Pp. 420.

1967 Symbols in Ndembu Ritual. In The Forest of Symbols: Aspects of Ndembu Ritual. Victor Turner, ed. Pp. 19-47. Ithaca: Cornell University Press.

1969 The Ritual Process: Structure and Anti-Structure. Chicago: Aldine Publishing Co.

1974 Liminal to Liminoid in Play, Flow, and Ritual: An Essay in Comparative Symbology. Rice Institute Pamphlet-Rice University Studies 60(3).

1986 The Anthropology of Performance. New York: PAJ Publications.

Van Gennep, Arnold.

2010[1960] The Rites of Passage. London: Routledge. 